\title{
El principio jurídico de la apariencia*
}

\author{
Angelo Falzea**
}

\section{Consideraciones introductorias}

En los tiempos modernos, la exigencia de hacer más ágiles las distintas formas de circulación jurídica de los bienes, ocasionada por la expansión del comercio y de los tráficos, así como por la intensificación del ritmo de las relaciones económicas, ha impuesto una protección reforzada de los terceros y, en sentido contrario, una menor garantía de los derechos preexistentes y de las situaciones jurídicas preconstituidas. A partir de la segunda mitad del siglo XIX, los ordenamientos jurídicos de los diversos países iban creando, a través de reiteradas medidas legislativas, excepciones cada vez más numerosas a las reglas tradicionales, mientras que la jurisprudencia iba extendiendo el ámbito de aplicación de dichas reglas; y la doctrina, por su parte, comenzaba a recoger en esbozos de sistematizaciones generales los nuevos temas que brindaban las leyes y la experiencia. En esta corriente innovadora, el lugar de vanguardia fue

Título original: «Apparenza», ahora en FALzEA, Angelo. Ricerche di teoria generale del diritto e di dogmatica giuridica, II, Dogmatica giuridica. Milán: Giuffrè, 1997, pp. 809-856. Traducción, autorizada por el autor, de León L. Leysser, doctor en Derecho Civil, profesor ordinario de Derecho Privado en la Pontificia Universidad Católica del Perú, y diplomado en Lengua y Cultura Italianas por la Università per Stranieri di Perugia (Italia).

** Angelo Falzea, decano de los civilistas italianos, nació el 26 de agosto de 1914. Obtuvo la licenciatura en Derecho en 1936 en la Universidad de Mesina, a la que su nombre ha estado vinculado, desde entonces, al igual que el de su excelso maestro, Salvatore Pugliatti (19031976). Ha sido profesor, entre otras materias, de Instituciones de Derecho Privado, Derecho Civil e Introducción a las Ciencias Jurídicas. Ejerció por casi veinte años (1969-1986) la presidencia de la Facultad de Derecho de la Universidad de Mesina, de la que hoy es catedrático emérito. Es miembro nacional de la Accademia dei Lincei, que reúne a los más ilustres representantes de la cultura italiana, y director de la prestigiosa Enciclopedia del diritto de la editorial milanesa Giuffrè. En 1991, se le otorgó el Premio Internacional Uberto Bonino para las Letras, Artes, Ciencia y Cultura, en reconocimiento a su «[...] contribución analítica a las ciencias jurídicas, en casi todos los temas del derecho civil y de la teoría 
para Alemania, donde las tendencias teóricas más acentuadas de los pandectistas y, en especial, de los autores e intérpretes del BGB, ${ }^{\mathrm{NT}}$ unidas a las particulares estructuras de las instituciones jurídicas de origen germano, facilitaron la elaboración de conceptos y principios que, al final, fueron objeto de una coherente y sistemática formulación en la teoría de la apariencia y, con un alcance más general, en la teoría de la confianza. ${ }^{1}$

Aquellas nuevas demandas - que en los países del common law habían podido reducirse a los principles of equity ${ }^{2}$ tuvieron mayores resistencias en las doctrinas francesa e italiana. La primera siguió el camino, bastante estrecho, del principio del error común, con un intento de extensión y forzamiento de los confines de este: aún hoy en día, en Francia, para justificar la conservación de las adquisiciones del heredero aparente, se recurre al principio en mención, el cual es utilizado también para otras hipótesis, relativas a la llamada propiedad

general del derecho, compromiso que ha perpetuado una tradición secular de prestigio del Ateneo de Mesina en este campo».

De su vasta obra recordaremos las monografías /l soggetto nel sistema dei fenomeni giuridici (Milán: Giuffrè, 1939); La condizione e gli elementi dell'atto giuridico (Milán: Giuffrè, 1941; reimpreso en 1979, por la ESI de Nápoles); La separazione personale (Milán: Giuffrè, 1943); L'offerta reale e la liberazione coattiva del debitore (Milán: Giuffrè, 1947); el volumen Introduzione alle scienze giuridiche (Milán: Giuffrè, 1975; la quinta edición es de 1996), y las compilaciones de ensayos Ricerche di teoria generale del diritto e di dogmatica giuridica (2 vols., Milán: Giuffrè, 1999 y 1997, respectivamente).

NT Abreviatura del Bürgerliches Gesetzbuch, el Código Civil alemán.

1 Son fundamentales, al respecto, las obras de MeYER, H., «Das Publizitätsprinzip», en D. B. R., Munich, 1909; Naendrup, Begriff des Rechtsscheins und Aufgabe der Rechtsscheinsforschungen, Münster, 1910; y de KRÜCKMANN, "Sachbesitz Rechtsbesitz Rechtsschein in der Theorie des gemeinen Rechts», en Arch. civ. Pr., CVIII (1912), p. 179 y ss. (del mismo autor cfr., anteriormente, «Nachlese zur Unmöglichkeitslehre», en Jherings Jahr., LVII (1910), pp. 1 y ss., especialmente, pp. 96 y ss.). También son de señalar: GIERKE, O., Deutsches Privatrecht, I, Leipzig, 1905, pp. 187 y ss., 552 y ss.; ReGELSBERGER, «Der sogenannte Rechtserwerb vom Nichtberechtigten», en Jherings Jahr., XLVII (1904), pp. 356 y ss.; FISCHER, «Sein und Schein im Rechtsleben», en Int. Wochenschr. für Wiss. Kunst u. Technik, 1909; StINTZING, «Besitz, Gewere, Rechtsschein», en Arch. civ. Pr., CIX (1912), pp. 347 y ss.; OERTMANN, «Grundsätzliches zur Lehre vom Rechtsschein», en Zeit für ges. Handelsr., vol. 95 (1930), pp. 443 y ss.; así como el sintético trabajo de CRISOLLI, «Publizitätsprinzip», en Hw. der Rechtsw., IV, Berlín-Leipzig, 1927, pp. 619 y ss. Sin embargo, algunos de los autores citados, especialmente Krückmann y Naendrup, daban al concepto de apariencia y a su ámbito de aplicación una extensión en tal medida exagerada (comprehensiva de la prescripción, la anulabilidad, la declaración de muerte presunta y hasta de... ¡la cosa juzgada!) que la teoría de la apariencia quedaba desacreditada, como hubo de decir Meyer (Vom Rechtsschein des Todes, Leipzig, 1912, pp. 13 y ss.). Incluso en una época menos lejana, Oertmann, a pesar de advertir la exigencia de un concepto restringido de apariencia jurídica (ob. cit., p. 457), hace confluir en la categoría respectiva figuras numerosas y heterogéneas (ob. cit., pp. 478 y ss.).

2 Cfr. EsSER, J. Grundsatz und Norm in der richterlichen Fortbildung des Privatrechts. Tubinga: 1956, p. 215. 
aparente. ${ }^{3}$ En Italia, en cambio, el intento consistió en brindar una formulación adherente al derecho positivo, para la cual se sacó el máximo provecho de referencias y alusiones normativas y, a la vez, de las doctrinas germanas. En dicho marco, se postularon las teorías de la protección de la expectativa ${ }^{4}$ y de la posesión de los derechos, ${ }^{5}$ antes de que se llegara a una franca e íntegra acogida de la teoría y del principio de la apariencia.

Como suele ocurrir en casos como estos, los primeros entusiasmos suscitados por la nueva teoría no se caracterizaron por la sutileza. No hubo preocupación por controlar si era posible transferir un principio elaborado para un sistema en particular, y se creyó que se podían encontrar aplicaciones de dicho principio en los más variados campos y en las más diversas instituciones: de la posesión a los títulos valores, de la publicidad al matrimonio, de los actos con fe pública a las sociedades mercantiles. ${ }^{6}$

El exceso de una aceptación acrítica como la descrita generó, por reacción, el exceso opuesto: se negó, con dureza y apriorismo, la utilidad de la teoría, e incluso su compatibilidad con los principios del sistema italiano. ${ }^{7}$ Sin embargo,

3 Planiol y Ripert (y Boulanger), Traité élém. droit civ., cuarta ed., III, París, 1951, pp. 733 y ss.; Josserand, Cours de droit civ. pos. franç., segunda ed., III, París, 1933, pp. 584 y ss.; Colin y Capitant, Cours élém. droit civ. franç., décima ed., III, París, 1950, pp. 565 y ss.; Cremieu, «De la validité des actes accomplis par I'héritier apparent», en Rev. trim. dr. civ., 1910, p. 39. En la doctrina francesa sobre el error común, cfr. los estudios de ValabrèguE, «De la maxime «Error communis facit ius»», en Revue crit., 1890; LonIEWskı, Essai sur le rôle actuel de la maxime "Error communis facit ius», Aix, 1905; MAZEAUD, H., "La maxime «Error communis facit ius»», en Rev. trim. dr. civ., 1924, p. 929.

4 Venezian, La tutela dell'aspettativa, Bolonia, 1900, ahora en sus Opere giuridiche, II, Roma, 1920, pp. 161 y ss.

5 Finzl, Il possesso dei diritti, Roma, 1915, estudio que tiene un precedente —si bien en otro plano- en la obra de BrINI, «Possesso delle cose e possesso dei diritti nel diritto romano», en los Studi giur. e stor. per I'VIII centenario dell'Università di Bologna, Roma, 1888, pp. 131 y ss., especialmente, pp. 144 y ss.

6 Son de recordar, especialmente, los estudios de Mossa, «El registro di commercio», en Studi sassaresi, 1921, y La dichiarazione cambiaria, Pisa, 1930 (véanse los extractos publicados en la Riv. dir. comm., 1930, I, pp. 305 y ss.) y de SOTGIA, Apparenza giuridica e dichiarazione alla generalità, Roma, 1930, y «Ancora in tema di apparenza del diritto», en Riv. dir. priv., 1936, I, pp. 121; además, de BolAfFl, «Le teorie dell'apparenza giuridica», en Riv. dir. comm., 1934, I, pp. 695 y ss. El concepto ha sido utilizado con mayor amplitud en el campo de las sociedades (SALANDRA, «Estensione e fondamento giuridico della responsabilità personale per le obbligazioni delle società irregolari», en Riv. dir. comm., 1928, II, p. 8; y del mismo autor, Le società irregolari nel diritto vigente, Roma, 1935, pp. 46 y ss., así como «Le società fittizie», en Riv. dir. comm., 1932, I, pp. 290, 305; DominEDÒ, Le anonime apparenti, Siena, 1931, p. 75; y véase también SotGiA, Società Commerciali irregolari, Milán, 1938); y en materia de títulos valores: cfr., especialmente: Mossa, La dichiarazione cambiaria, pp. 73 y 102 y ss.; SOTGIA, Apparenza, pp. 206 y ss.; y MESSINEO, I titoli di credito, segunda ed., I, Padua, 1933, pp. 26 y ss.; igualmente, y de lo más reciente: FenRI, G., I titoli di credito, en Trattato Vassalli, Turín, 1952, pp. 51-54 (y allí, las referencias de las notas 3 y 8).

7 Especialmente: Stolfl, G., L'apparenza del diritto, Módena, 1934. Entre los más vivaces opositores a la teoría se encontraba también VERGA, "Osservazioni in tema di apparenza», en Riv. dir. priv., 1940, pp. 193 y ss. 
las primeras posiciones contrarias fueron seguidas por una reflexión más ponderada y serena. ${ }^{8}$ Por un lado, el concepto de apariencia fue presentándose claramente como inutilizable en ciertos fenómenos que la doctrina alemana cita, más bien, como sus aplicaciones típicas y ejemplares — la publicidad, la posesión, los títulos valores-; por otro lado, y con arreglo a las directrices de nuestro derecho positivo, tenía lugar un proceso de revisión que no ha producido resultados satisfactorios hasta el momento, pero que ha permitido, de todas maneras, establecer la existencia de casos notables en los cuales resulta indispensable el recurso a un principio de apariencia, y donde esta categoría tiene un empleo legítimo y fructífero. En el estado de cosas actual, se puede afirmar que la idea de la apariencia, a pesar de incertidumbres y escepticismos, ${ }^{9}$ es reconocida con carácter general por la doctrina italiana. ${ }^{10}$ Nuestra jurisprudencia, por su parte, ha contribuido en gran medida a disipar las dudas subsistentes, con una obra pujante que, si bien ha extendido en demasía la interpretación de las disposiciones legales, tiene igualmente el mérito de haber determinado, de forma más o menos explícita, las condiciones bajo las cuales es posible una aplicación analógica de las normas que regulan los distintos casos de apariencia.

La definición teórica de la categoría y la construcción de la institución jurídica correspondiente deben realizarse al amparo de las normas de nuestro derecho positivo en las cuales se prevén y regulan, con seguridad, fenómenos de apariencia, y con el sostén de la elaboración doctrinal y jurisprudencial que han permitido debatir en torno del principio y su ámbito de aplicación, de su casuística y sus problemas principales. Solo con extrema cautela - hay que advertirlo de inmediato - se pueden invocar las investigaciones y teorías de la doctrina alemana. En efecto, aunque tales investigaciones y teorías han permitido identificar el sistema de intereses que constituye la base de la institución, ellas han confundido también, muchas veces, a los intérpretes del derecho italiano, que no han tenido en cuenta, como es debido, las profundas diferencias que dividen y oponen el ordenamiento alemán y el nuestro.

En este punto, hay que llamar la atención sobre los aspectos más importantes de aquella diversidad, a fin de aclarar, desde el comienzo, las razones que imponen un planteamiento autónomo del estudio del fenómeno, conforme a

8 Un ejemplo significativo fue la voz enciclopédica «Apparenza», de D'AmeLıo, publicada en el Nuovo Dig. it., I, Turín, 1937.

9 En dicho sentido se pronuncia, sobre todo, PugliatTI, La trascrizione, Milán, 1957, pp. 252 y ss.

10 Son de señalar los estudios de CORRADO, La pubblicità nel diritto privato, Turín, 1947, pp. 1 y ss.; Mengoni, L'acquisto "a non domino», Milán, 1949, pp. 75 y ss.; y de SACCo, La buona fede nella teoria dei fatti giuridici di diritto privato, Turín, 1949, pp. 52 y ss. Es particularmente notable por sus aportaciones teóricas, además, la obra de MonAcCiAni, Azione e legittimazione, Milán, 1951, pp. 132 y ss. 
la legislación italiana. En la doctrina alemana, luego de los interminables debates iniciales y de las hondas discrepancias de opinión consiguientes, ${ }^{11}$ se fue afirmando, cada vez con mayor fuerza, la idea de ligar la apariencia con un principio general de publicidad (Publizitätsprinzip), inspirado en la exigencia de proteger la fe pública. Dicho principio comprende todos los casos en que el acto realizado por el tercero con un sujeto que no tiene la titularidad del derecho es eficaz, de todos modos, como si hubiese sido realizado con el titular, siempre que un título de investidura formal de aquel sujeto cree una situación de confianza del tercero. La investidura formal en un derecho subjetivo que realmente no existe se presenta en varias hipótesis: de la posesión a los instrumentos de fe pública, e incluso a las diversas figuras de publicidad. En todos estos casos, el presupuesto de la protección del tercero es que la confianza se encuentre justificada por un título formal, en el cual se basa, en definitiva, la apariencia del derecho. Así pues, la apariencia no indica otra cosa que el operar de los fenómenos formales - por razones de confianza - aun cuando la situación jurídica asumida formalmente por ellos no exista en la realidad. En esta concepción, entonces, la idea de apariencia no solamente se considera compatible, sino más bien ligada, esencialmente, con la idea de formalismo, a tal punto que la posesión, inclusive, es configurada como título formal de investidura. ${ }^{12}$

En el derecho positivo italiano el panorama es distinto. Las fattispecie de apariencia están constituidas por situaciones de hecho sustanciales que están al margen de la influencia del formalismo jurídico, y dicha característica representa su razón justificativa principal. Es cierto que la publicidad, los actos con fe pública y las demás figuras de igual tipo tienden a realizar la protección del mismo sistema de intereses que el derecho quiere garantizar con el régimen de la apariencia. Empero, las formas de la protección jurídica son radicalmente distintas en las dos categorías de fenómenos. El formalismo, al manifestarse en estructuras rígidas y tipificadas, realiza una protección más intensa del tercero, porque dispensa de una justificación específica de su conducta cuando él puede invocar el contenido del documento formal: esta protección, en particular, o bien no tiene ningún límite en el conocimiento del tercero sobre la disconformidad entre la situación jurídica real y la situación resultante del documento negativo, o bien tiene solo un límite negativo, cuando se presente un entendimiento doloso o un estado de mala fe.

\footnotetext{
Sobre las cuales véase lo señalado, una vez más, por OerTMAnN, ob. cit., p. 443.

12 Jeder Formalismus stütz das Publizitätsprinzip, afirma CRISOLLI, Publizitätsprinzip, p. 620. Considérese la clasificación de las fattispecie en las cuales, en aplicación del principio de publicidad, se protege la buena fe, según la propuesta de WeLLSPACHER, Vertrauen auf äussere Tatbestände im b. R., Viena, 1906: en esta clasificación los künstliche äussere Tatbestände, constituidos esencialmente por los registros y figuras análogas a estos, se contraponen a lo natürliche äussere Tatbestände, los cuales están constituidos por la posesión, entendida, justamente, como título de legitimación, y por los documentos privados.
} 
En la apariencia, en cambio, y según el enfoque del legislador italiano, la protección del tercero resulta necesaria por la ausencia de un documento o de un título formal, y debe apoyarse por fuerza, por lo tanto, en una situación de buena fe, específicamente justificada por una situación de hecho que sea objetivamente capaz de hacer caer en engaño a un tercero cualquiera. Esta, ni más ni menos, es la razón precisa de su utilidad. No hay duda de que su ámbito de aplicación resulta más restringido, pero dentro de dicho ámbito se desenvuelve una institución jurídica autónoma, y el término apariencia no pierde, en modo alguno, el significado que le es propio, distintamente de lo que ocurre cuando se designa con él, sin ninguna necesidad esencial, la manera de operar del formalismo respecto de los terceros. En el fondo, este distinto grado de utilidad explica por qué en Italia la institución va ganando en amplitud, mientras que en Alemania, en la actualidad, se escucha hablar cada vez menos de apariencia. Esta es configurada, por lo general, como expresión del principio de publicidad, en el cual, por dicha razón, tiende a resolverse completamente.

\section{Noción jurídica de apariencia: situación de hecho que manifiesta como real una situación jurídica no real}

En principio, la doctrina concuerda en considerar que la apariencia se relaciona con una situación jurídica y, más precisamente, con un derecho subjetivo: se habla, justamente, de apariencia jurídica, de apariencia del derecho, de apariencia de la situación jurídica ${ }^{13} \mathrm{o}$, con una expresión específicamente construida, de apparentia iuris..$^{14}$ Una situación jurídica aparenta existir, aunque realmente no existe. Esta circunstancia, de aparentar pero no ser, hace que entren en juego intereses humanos relevantes que la ley no puede ignorar. El problema consiste, entonces, en identificar el significado jurídico del fenómeno, y su categoría teórica correspondiente.

En este punto, lo importante es, más que buscar una definición puntual, trazar un cuadro sistemático de conceptos que permita establecer las relaciones $y$, por lo tanto, las distinciones necesarias entre la figura jurídica de la apariencia y las demás figuras - posesión, publicidad, actos con fe pública, títulos formales - con las cuales ella, frecuentemente, es confundida.

Partiendo de la inmediata sugestión etimológica del término, se puede observar que la apariencia es un aparecimiento: el aparecimiento de lo irreal como real — por lo cual es claro que el aparecimiento, en tanto denominador universal

Puglattı, ob. cit., p. 252, emplea esta última fórmula, como más amplia que la original: «apariencia del derecho subjetivo».

14 Nuvolone, Il possesso nel diritto penale, Milán, 1942; Funalolı, C. A., «A proposito d'"apparentia iuris"», en Riv. dir. civ., 1942, I, pp. 128 y ss. 
de los fenómenos, es una categoría mucho más amplia que la apariencia, porque pueden darse, por ejemplo, además del aparecimiento de lo irreal como real, el aparecimiento de lo real como real, el aparecimiento de lo irreal como irreal, y también un aparecimiento neutro, indiferente a toda realidad o irrealidad- Pero para entrar, sin más, en el terreno de los conceptos útiles para la presente exposición, es importante afirmar, ante todo, que la apariencia no es un aparecimiento opaco, un puro hecho que únicamente se revela a sí mismo, porque un fenómeno que se limita a revelarse a sí mismo jamás puede ser aparente. Este fenómeno se presenta como aquello que es; la apariencia, por el contrario, surge solo cuando un fenómeno hace que otro fenómeno, además de sí mismo, aparezca, y lo hace aparecer como real, aunque es irreal. Advertimos, entonces, que la apariencia tiene una estructura compleja. Ella es - anotémoslo vagamente, por ahora - un quid relacional: el aparecimiento es un transparentar, un fenómeno que aparece a través de otro fenómeno. Es imperioso distinguir bien el fenómeno que hace aparecer del fenómeno que es hecho apsarecer: la diferencia principal es que el primero de ellos se muestra en su presencia material, mientras que el segundo no está presente materialmente, sino que es indicado solo por alusión o invocación. Otra razón es que la apariencia afecta solo al segundo fenómeno y no al primero: solo el segundo aparece como real pero no lo es; el primero, en cambio, es real; es más, es inmediatamente real. Todo ello puede intuirse cuando se pasa al análisis de las diversas fattispecie de apariencia nominadas en la legislación italiana. En la fattispecie del heredero aparente, ${ }^{\mathrm{NT}}$ por ejemplo, hay algo que parece existir, pero que no existe en realidad, o sea, la calidad de heredero; empero, hay un sujeto que realiza ciertos actos y que se encuentra en ciertas situaciones, y son dichos actos y situaciones los que dan lugar a inferencias falsas.

Con estas reflexiones, la figura de la apariencia es asimilada a un esquema general de relación: la relación por la cual un fenómeno materialmente presente e inmediatamente real hace aparecer o — como también podemos anotarlo (con un término más usual entre los juristas) — manifiesta otro fenómeno, que no está presente materialmente y que no es inmediatamente real. En este punto conviene advertir —y lo veremos mejor más adelante— que la apariencia es solo un caso particular de este esquema, el cual puede tener, además, un doble plano de aplicación. Se le puede aplicar, sobre todo, en el plano subjetivo, en

NT La regulación de esta figura en el Código Civil peruano ha sido construida siguiendo el modelo italiano. En nuestro Código, en efecto, se dispone que «[...] la acción reivindicatoria procede contra el tercero que, sin buena fe, adquiere los bienes hereditarios por efecto de contratos a título oneroso celebrados por el heredero aparente que entró en posesión de ellos» (artículo 665, párrafo 1). En el Código Civil italiano, el artículo 534, subtitulado derechos de los terceros, estipula (párrafo 2) que «[...] quedan a salvo los derechos adquiridos, por efecto de convenciones a título oneroso con el heredero aparente, por los terceros que prueben haber contratado de buena fe». 
cuyo caso se le interpretará subjetivamente. En el lenguaje común, en efecto, la voz apariencia denota un fenómeno subjetivo, una situación análoga, si no es que idéntica, a la situación subjetiva del error. Pero también se habla de apariencia en sentido objetivo, por ejemplo, cuando se dice que el movimiento del sol en torno de la Tierra es un movimiento aparente, en cuyo caso la apariencia no se presenta como mera ilusión de la conciencia individual, sino como contenido de la experiencia posible del individuo promedio de la entera humanidad o, cuando menos, de un determinado ambiente social. Preeminente y decisivo para la definición del concepto jurídico de apariencia es, precisamente, el segundo significado del término, y la doctrina concuerda en configurar los casos ejemplares del fenómeno, y el fenómeno mismo en su generalidad, sobre bases esencialmente objetivas. Es acreedor aparente, por ejemplo, no simplemente aquel sujeto cualquiera al que el tercero atribuye, por error, la calidad de acreedor, sino solo aquel sujeto que situaciones objetivas, socialmente apreciables, inducen a considerar como efectivo titular del crédito. Sin embargo, si es necesario distinguir la apariencia, en sentido objetivo, del error, que es subjetivo, no es menos necesario admitir el íntimo nexo que media entre los dos fenómenos; un nexo que se puede apreciar, en los hechos, en todos los casos de apariencia. La calidad de acreedor aparente — para retomar el ejemplo que acabamos de proponer - no es el producto de una simple representación errónea del acreedor; empero, el tercero debe incurrir verdaderamente en un error, a fin de que se produzca, en ventaja suya, el efecto liberatorio previsto en el artículo 1189 del Código Civil. ${ }^{\mathrm{NT}}$

Para entender y definir en un marco teórico claro el concepto objetivo de apariencia es necesario aplicar el esquema general antes descrito en el plano objetivo, e interpretar objetivamente, por lo tanto, la relación por la cual un fenómeno manifiesta otro fenómeno.

Un concepto objetivo de manifestación, justamente en el sentido requerido, es familiar a los juristas, que lo emplean en la teoría del negocio jurídico, donde se distingue, ni más ni menos, entre la voluntad —o, por mejor decir, la volición-, que es un hecho subjetivo e individual, y la manifestación de dicha voluntad, que es, en cambio, un hecho socialmente apreciable. Mucho menos familiar a la ciencia jurídica actual es, por el contrario, otro concepto, que también es fundamental para la teoría del negocio. La objetividad de la manifestación no se agota en su mera exterioridad y materialidad —en general,

NT Código Civil italiano (1942): «1189. Pagamento al creditore apparente.- II debitore che esegue il pagamento a chi appare legittimato a riceverlo in base a circostanze univoche, è liberato se prova di essere stato in buona fede».

[«1189. Pago al acreedor aparente.- El deudor que realiza el pago a quien parece estar legitimado para recibirlo sobre la base de circunstancias unívocas, queda liberado si prueba haber tenido buena fe»]. 
objetividad no equivale a materialidad -.${ }^{15}$ No solo se requiere distinguir entre el aparecimiento subjetivo y la manifestación objetiva: hay que subdistinguir también la manifestación en dos momentos, ambos objetivos, pero que no son materiales por igual. Ello puede comprenderse sin dificultad, aunque se considere ínfimamente que, en el fondo, la manifestación objetiva de la que se habla se apoya siempre en una realidad que jamás es meramente material: la realidad de un hecho social humano y, para ser más precisos, de una relación de significación socialmente apreciable, que está al margen, en gran medida, de las apreciaciones individuales de los sujetos en particular. Es más, se debe afirmar, en síntesis, que la relación por la cual un fenómeno manifiesta objetivamente otro fenómeno no es otra cosa que esta relación de significación social: la relación en virtud de la cual el primer fenómeno significa socialmente el segundo fenómeno, es decir, que lo hace aparecer en un campo de experiencia pública. Ahora bien, en toda relación de significación se distingue un signo material y un significado inmaterial. El signo material es, precisamente, el fenómeno significante o manifestante; el significado inmaterial, en cambio, es el fenómeno significado o manifestado. En la objetividad de la manifestación, entonces, es necesario distinguir dos aspectos: el aspecto objetivo-material del fenómeno manifestante y el aspecto objetivo-inmaterial del fenómeno manifestado. Aquí, el caso del negocio jurídico es ejemplar, porque muestra con particular evidencia estos dos aspectos, ambos objetivos, pero no materiales por igual, y que son, en resumen, el signo y el significado de la actividad socialmente significativa desarrollada por los sujetos.

Es menester recurrir, una vez más, y principalmente, a los estudios en materia de negocio jurídico, para efectuar otra distinción que juega un papel muy importante en la teoría de la apariencia. En el genus 'manifestación' se acostumbra distinguir entre la manifestación en sentido estricto, que es un comportamiento unívocamente orientado según cierto programa práctico — la pro herede gestio, por ejemplo-, y la declaración, que es un hecho de lenguaje, escrito, oral o mímico - la aceptación expresa de la herencia, por ejemplo-. Habiendo aclarado que la manifestación en general consta siempre de una relación de significación social, estamos en condición de asimilar la última diferencia, entre manifestación en sentido estricto y declaración, a la diferencia entre dos subtipos de la relación de significación, que podemos caracterizar, respectivamente, como significación por señales y significación por simbolos — de acuerdo con una nomenclatura

15 Estas ideas sobre el negocio y sobre la estructura de la manifestación negocial han sido desarrolladas en nuestra obra Teoria della efficacia giuridica, Milán, 1951 (edición provisional). Ellas han sido retomadas y comentadas desde un punto de vista filosófico por DE Stefano, R., Il problema del diritto non naturale, Milán, 1955 (en esta obra en encontrará también una muy general fundamentación del concepto de objetividad inmaterial, y de su uso empírico y científico. Cfr. pp. 131-158). 
común en los estudios semánticos modernos-. Grosso modo, un signo es señal o símbolo, en atención a si permite inferir la realidad o si se limita a evocar la estructura ideal del fenómeno significado. La antigua distinción entre lo que se manifiesta rebus ipsis ac factis, o sea, según conexiones empíricas reales, y lo que se manifiesta verbis vel scriptis, o sea, con medios puramente ideales y simbólicos, ilustra bien esta diferencia. Naturalmente, la manifestación en sentido estricto, mucho más que la simbólica, es cercana a la realidad, pero no por ello el fenómeno manifestado es necesariamente real. Las señales pueden ser falsas: y la apariencia es, precisamente, una falsa señalación de la realidad.

Lo anterior basta para describir cabalmente y definir la situación de la apariencia. En la apariencia, un fenómeno - materialmente presente e inmediatamente real — manifiesta otro fenómeno — ni materialmente presente ni inmediatamente real- Y Y lo manifiesta objetivamente, a través de signos o relaciones de significación socialmente apreciables. Lo manifiesta, no a través de símbolos, sino rebus ipsis ac factis, sobre la base de normales conexiones empíricas. Lo manifiesta como real, aunque no es real, porque las conexiones empíricas, abstractamente verificables en la normalidad de los casos, están ausentes en el caso concreto.

Para resumirlo todo, en una breve definición: la apariencia, objetivamente entendida, es el aparecimiento de lo irreal como real, dentro de un campo de experiencia pública, en virtud de relaciones socialmente reconocidas de significación no simbólica. Esta definición permite proponer distinciones precisas entre la apariencia y las demás figuras que un análisis nada atento ha hecho confluir en ella: en particular, respecto de la posesión — hecho neutro, desprovisto de toda fuerza de significación - y de los actos y documentos formales, que tienen capacidad significativa, pero meramente simbólica.

\section{Delimitación del concepto de apariencia respecto de las situaciones de hecho que no manifiestan otra situación (posesión)}

Desarrollando las consideraciones expuestas, así como las distinciones a que se ha hecho referencia al final del acápite precedente, podemos proceder a la delimitación conceptual más precisa del fenómeno de la apariencia, atendiendo, específicamente, al régimen dictado por nuestro derecho positivo.

La apariencia, como situación de hecho que manifiesta y hace aparecer como real una situación jurídica no real, ${ }^{16}$ puede presentarse solo cuando exista una situación capaz de desplegar una fuerza de señalación de realidad. Por lo

6 Como puede intuirse, solo situaciones de hecho pueden fundar una fattispecie de apariencia: cfr., por todos, WellsPacher, ob. cit. 
tanto, no pueden dar lugar a hipótesis de apariencia aquellos hechos que se caracterizan por tener una estructura opaca, y que, por ello, no son capaces de señalar nada, salvo su propia existencia. Por la misma razón, y por lo menos en el derecho positivo italiano, la fattispecie de la posesión no puede ser considerada, sino incorrectamente, como figura de apariencia.

No es de descartar, ciertamente, que en aquellos ordenamientos - como el alemán- en los cuales se asigna a la traditio un papel constitutivo en la adquisición de la propiedad mobiliaria, en atención a que existe un elevado índice de probabilidad sobre la coincidencia entre situación posesoria y derecho de propiedad, la primera pueda actuar como signo del segundo, y generar, de tal manera, una fattispecie de apariencia, cuando ella no vaya acompañada del derecho de propiedad. En cambio, cuando la ley no liga la posesión con la propiedad con un medio semejante, ni con otra relación así de estricta, no puede tener lugar el fenómeno de la apariencia. Como es sabido, el ordenamiento italiano protege la posesión, exclusivamente, por su realidad intrínseca, y no porque ella sea considerada como una normal manifestación externa del derecho de propiedad: se exige que el poseedor, para beneficiarse de tal protección jurídica, asuma un comportamiento correspondiente al ejercicio de la propiedad o de otro derecho real (artículo 1140 del Código Civil), ${ }^{\mathrm{NT}}$ y ello se hace solo con el fin de definir la fattispecie misma de la posesión. ${ }^{17}$ Basta considerar que la protección de la posesión se exterioriza en efectos jurídicos distintos de los del derecho real respectivo. Debe descartarse, en consecuencia, que la posesión, en el ámbito del derecho italiano, se pueda definir como un fenómeno de apariencia.

Esta configuración tampoco sería legítima en la hipótesis específica de las adquisiciones a non domino, a pesar de que lo contrario se ha sostenido con insistencia. Aquí también, la correcta consideración del fenómeno ha sido impedida por la apurada transposición a nuestro derecho de criterios elaborados en relación con ordenamientos jurídicos distintos. La formulación más

NT Código Civil italiano:

«1140. Possesso.- Il possesso è il potere sulla cosa che si manifesta in una attività corrispondente all'esercizio della proprietà o di altro diritto reale».

[1140. Posesión.- La posesión es el poder sobre la cosa que se manifiesta en una actividad correspondiente al ejercicio de la propiedad o de otro derecho real].

Para el codificador peruano, equivalentemente, la posesión es «[...] el ejercicio de hecho de uno o más poderes inherentes a la propiedad» (artículo 896).

17 Una tesis opuesta ha sido sostenida, en Italia, por Nuvolone, ob. cit., p. 19 y ss. (véase, sin embargo, lo que ya anotaba MESSINEO, I titoli di credito, l, p. 31), cuyos argumentos han sido fácilmente criticados por Funalol, C. A., ob. cit., pp. 128 y ss.; Montel, La disciplina del possesso nel cod. civ. it., Turín, 1947, p. 19; y por MenGonl, ob. cit., pp. 136 y ss. Por otro lado, también en la doctrina alemana, no obstante la particular función de la traditio, se ha terminado negando que la posesión constituya, de por sí, un fenómeno de apariencia: véase, por todos, OerTMAnN, ob. cit., pp. 451 y ss. 
moderna y coherente de la tesis opuesta explica, en términos ciertamente persuasivos, la fattispecie prevista en el artículo 1153 del Código Civil, ${ }^{\mathrm{NT}}$ considerando la posesión del enajenante como signo de la titularidad del derecho real $^{18} \mathrm{y}$, por ello, como indicio exterior de apariencia, necesario y suficiente como para justificar objetivamente la buena fe del adquirente. ${ }^{19}$ Sin embargo, en esta teoría se reflejan las mismas contradicciones que han hecho rechazar, en nuestro derecho positivo, la tesis que aprecia en la posesión una forma de publicidad de hecho del derecho real. ${ }^{20}$ Ella ya ha sido objeto de una crítica analítica y definitiva en la doctrina, a la cual podemos remitir. ${ }^{21}$ Aquí solo nos limitaremos a recordar que en las adquisiciones a non domino, para despojar a la posesión de la función de indicio de apariencia, es válida la decisiva observación de que en esta fattispecie la posesión del enajenante no propietario está completamente privada de relevancia jurídica. ${ }^{22}$ Este argumento - junto con la observación de que la buena fe del adquirente no es requerida al momento de la adquisición, sino al momento de la entrega - es válido para demostrar que la ley no vincula la eficacia de las adquisiciones a non domino con la apariencia del derecho de propiedad, fundada en la posesión del enajenante. ${ }^{23} \mathrm{La}$ diferencia entre los dos fenómenos se refleja también en su distinto modo de operar. En la apariencia, como veremos, la ley realiza una recuperación parcial

NT Código Civil italiano:

«1153. Effetti dell'acquisto del possesso.- Colui al quale sono alienati beni mobili da parte di chi non ne è proprietario, ne acquista la proprietà mediante il possesso, purché sia in buona fede al momento della consegna e sussista un titolo idoneo al trasferimento della proprietà. La proprietà si acquista libera da diritti altrui sulla cosa, se questi non risultano dal titolo e vi è la buona fede dell'acquirente.

Nello stesso modo si acquistano i diritti di usufrutto, di uso e di pegno".

[1153. Efectos de la adquisición de la posesión.- Aquel al que son enajenados bienes muebles por parte de quien no es propietario de estos, adquiere su propiedad mediante la posesión, siempre que tenga buena fe al momento de la entrega, y exista un título idóneo para la transferencia de la propiedad.

La propiedad se adquiere libre de derechos ajenos sobre la cosa, si estos no resultan del título y si existe buena fe en el adquirente.

De la misma manera se adquieren los derechos de usufructo, de uso y de prenda».

18 Cfr. BolafFI, ob. cit., p. 145.

19 Especialmente: Carnelutti, Teoria della circolazione, Padua, 1933, pp. 174 y ss. Cfr. BolafFl, loc. cit., p. 145 y, para otras referencias bibliográficas, MENGONı, ob. cit., p. 141, nota 2.

20 Al respecto, reenviamos al exhaustivo y definitivo análisis de PugliatTI, ob. cit., pp. 277 y ss.

21 En particular: Stolfi, G., ob. cit., pp. 23 y ss.; Corrado, ob. cit., pp. 207 y ss.; MenGonl, ob. cit., pp. 141 y ss.; Pugliatti, ob. cit., pp. 289 y ss.

22 El argumento es colocado por la doctrina como fundamento de la crítica a la concepción opuesta. Cfr. Coviello, N., Della trascrizione, segunda ed., I, Nápoles-Turín, 1914, p. 9; Stolfl, G., ob. cit., pp. 24 y ss.; CorRado, ob. cit., pp. 208 y ss.; MenGONI, ob. cit., pp. 139 y ss.; Puglatti, ob. cit., pp. 288 y ss.

23 Observaba Covielto, N., ob. cit., p. 9, que la ley requiere la buena fe del adquirente, pero no que esta buena fe, para ser relevante, tenga que fundarse en la posesión del enajenante. 
de la fattispecie irregular, al reconocer los efectos jurídicos relativos al tercero de buena fe. En las adquisiciones a non domino, en cambio, se constituye una nueva fattispecie jurídica, de la cual el negocio traslativo — de por sí incapaz de tener algún efecto jurídico, por defecto de legitimación - constituye un elemento necesario, pero del todo insuficiente, porque debe ser complementado por la entrega de la cosa y la buena fe del adquirente; su eficacia, además, es de un tipo distinto, si se le compara con la del negocio traslativo, pues da lugar a una adquisición a título originario, mientras que tal negocio produciría una adquisición a título derivativo. Es por ello que la fattispecie de las adquisiciones a non domino ha sido asociada con la usucapión, como hipótesis de usucapio momentanea. ${ }^{24}$

\section{Delimitación del concepto de apariencia respecto de las situaciones de hecho que simbolizan situaciones jurídicas sin hacer aparecer la realidad (declaraciones, títulos formales, actos con fe pública, publicidad)}

Otros fenómenos para los cuales se invoca la categoría de la apariencia pueden ser excluidos, fácilmente, del ámbito de esta, sobre la base de nuestras definiciones. De las diversas aplicaciones, en mayor o menor medida plausibles, que se han intentado en la doctrina, consideraremos únicamente las más importantes.

Algunos han tratado de definir el problema de las relaciones entre voluntad y declaración — sobre todo en relación con los terceros-, justamente, como un fenómeno de apariencia, y se ha afirmado que la apariencia se insinúa de forma espontánea en la discrepancia entre voluntad y declaración. ${ }^{25}$ Este equívoco es alimentado por aquella concepción que propone explicar el negocio jurídico en términos de confianza, en atención a que la apariencia es considerada un caso ejemplar de protección de la buena fe de los terceros.

Aquí no interesa replicar que en la hipótesis en discusión la realidad manifestada es la voluntad, que no es una situación jurídica, sino un hecho psíquico. En cambio, la apariencia es siempre una apariencia de derecho, es decir, apariencia de una situación jurídica. Tampoco viene al caso replicar que la

24 Sin embargo, y para nuestro caso, se ha hablado de una subsanación del negocio traslativo viciado por el defecto de legitimación del enajenante. Cfr., pero solo en líneas generales, Bonfante, Corso di diritto romano, II, 2, p. 243. la crítica de MenGoni, ob. cit., p. 144, en principio exacta, se realiza, empero, con argumentos no decisivos.

25 Cfr. Dominedò, Le anonime apparenti, p. 90; Mossa, La dichiarazione cambiaria, p. 79; BolafFl, ob. cit., p. 148; SOTGIA, "Ancora in tema di apparenza del diritto», pp. 122 y ss. MENGONI, ob. cit., pp. 109 y ss., a pesar de descartar que las relaciones entre voluntad y declaración puedan explicarse recurriendo al concepto técnico de apariencia, sugiere un acercamiento que es inexacto (especialmente en lo tocante al papel de la voluntad) y artificioso. 
apariencia — como veremos mejor más adelante- puede incidir solo como presupuesto de eficacia del acto o negocio, y no como elemento constitutivo. ${ }^{26}$ Lo importante es aclarar, más bien, que la declaración no es indicio de realidad, y no se puede apelar a ella, por lo tanto, para justificar el convencimiento de la existencia de la voluntad que debería representar su contenido. Así, en el fenómeno de la simulación, la protección del tercero — que hubiere adquirido del titular aparente, o que haya realizado, como acreedor de este último, actos de ejecución sobre bienes objeto del contrato simulado- no se funda en la inoponibilidad al tercero de buena fe de la discrepancia entre voluntad y declaración ${ }^{27} \mathrm{ni}$, por ello, en la apariencia de la voluntad. Dicha protección se funda en la apariencia de la titularidad del derecho: apariencia que está constituida, en primer lugar, por el contrato simulado, pero también, y especialmente, por el comportamiento global de los simuladores, idóneo para generar en los terceros el erróneo convencimiento sobre la titularidad. En algunos casos, la ley no permite oponer al tercero la ausencia de la voluntad declarada, porque no considera relevante la apariencia de la voluntad, sino que se limita a dictar un reglamento de intereses que se realiza "[...] restringiendo la posibilidad de interponer o la eficacia de la acción de nulidad». ${ }^{28}$ Si fuera verdad que en algunas figuras de declaración — que tendrían como característica el estar dirigidas hacia la generalidad y que, por ello, se contrapondrían a los negocios jurídicos— la obligación nace "[...] por voluntad de la ley, en tanto ha surgido la declaración, y como quiera que ella hubiere surgido», ${ }^{29}$ sin que se requieran «[...] ni la voluntad en sentido tradicional, ni el propósito del declarante», ${ }^{30}$ lejos de demostrarse la presencia de una aplicación del fenómeno de apariencia, se acreditaría más bien lo contrario: en la suscripción del título valor, en la adhesión a una sociedad o en el apoderamiento, la declaración tendría efectos jurídicos de por sí, como fattispecie autosuficiente, y resultaría negada a priori toda relevancia jurídica a la voluntad y, por la misma razón, a la apariencia de la voluntad. ${ }^{31}$

26 Para estos realces, véase Oertmann, ob. cit., p. 461; Mengoni, ob. cit., p. 111.

27 Véase, en sentido contrario, SotGiA, "Ancora in tema di apparenza», p. 152. Cfr. también D’AMELIO, «Apparenza», p. 551. Aquí no interesa tomar posición sobre el problema relativo al fundamento del fenómeno de la simulación y su interpretación en términos de divergencia entre voluntad y declaración, o bien en términos de causa del negocio jurídico. Reenviamos, en todo caso, a la monografía de PUGLIATTI, "La simulazione nei negozi unilaterali», ahora en su volumen Diritto civile, Milán, 1951, pp. 539 y ss., y, en lo tocante a la apariencia, a Mengoni, ob. cit., pp. 104 y ss. No es de seguir la crítica de Verga, ob. cit., pp. 196 y ss.

28 Stolfi, G., ob. cit., p. 14.

9 Sotgia, Apparenza.

30 SotGia, ob. cit., p. 213, quien hace eco de Mossa, ob. cit., pp. 116 y ss.

31 Cfr. también SACCO, ob. cit., p. 64. 
Los hechos de significación simbólica y de lenguaje - los documentales y formales, en particular - han sido asimilados a la figura de la apariencia no solamente en relación con el fenómeno de la voluntad, sino también con la situación jurídica a la cual ellas pueden hacer remisión. Así, se ha recurrido a la idea de apariencia en lo que atañe a los títulos formales de legitimación, ${ }^{32}$ los actos con fe pública ${ }^{33}$ y los hechos de publicidad, ${ }^{34}$ en los casos de disconformidad entre la situación jurídica representada en ellos y la situación jurídica real. Dicho recurso ha parecido ser más legítimo porque el formalismo, que tiene tres diferentes ejemplos en las hipótesis que se acaban de señalar, constituye un medio de protección de la buena fe de los terceros. Solo que aquí, fuera del aspecto práctico en general —el cual se expresa, por lo demás, en contextos de intereses distintamente considerados-, no existe ningún elemento técnico de significado apreciable que permita atraer las hipótesis indicadas hacia el ámbito de aquella idea. Hay, más bien, datos generales que se pronuncian en sentido contrario.

$\mathrm{Al}$ respecto, bastaría la observación preliminar de que las declaraciones en que consisten los títulos formales de legitimación, los actos con fe pública y los hechos de publicidad no tienen la capacidad intrínseca de manifestar como existente ninguna realidad jurídica, para descartar que la protección de los terceros, frente a declaraciones de dicho género, se pueda fundar en un fenómeno de apariencia. Si la ley protege a los terceros en caso de que las declaraciones formales no correspondan a realidad jurídica enunciada por ellas, lo hace, no porque las declaraciones tengan la fuerza de hacer argumentar la existencia de esta realidad jurídica, sino porque frente a hechos declarativos de dicha naturaleza, la ley exonera al sujeto de la determinación de la realidad

32 Para los títulos valores en particular: FeRRI, G., ob. cit., pp. 51 y ss., y las referencias bibliográficas allí indicadas.

33 En especial, BolafFI, ob. cit., p. 134. Este fenómeno, que, en su acepción técnica, se considera limitado a aquellos casos en los cuales la administración, en fuerza de su competencia específica, declare la legitimidad de un acto, haciendo surgir, así, la fe pública en la validez y, por lo tanto, en la eficacia del acto (véase PugliatTı, La trascrizione, p. 239), se remite a la conocida hipótesis de la administración pública del derecho privado, ilustrada por ZANOBINI, "L'amministrazione pubblica del diritto privato», en Riv. dir. pubbl., 1918, I, pp. 169 y ss., ahora en su Corso di diritto amministrativo, V, Milán, 1950, pp. 173 y ss. La doctrina ha subrayado el limitado campo de aplicación de los actos de fe pública en el derecho italiano, así como la incertidumbre sobre su identificación (BOLAfFI, ob. cit., p. 138; PUGLIATTI, loc. ult. cit.). Se citan la declaración del funcionario del estado civil en la celebración del matrimonio y la inscripción en el registro de las empresas; sin embargo, también respecto de estos ejemplos existen discrepancias (véase, para el segundo caso, entre otros, PAVOnE LA Rosa, II registro delle imprese, Milán, 1954, p. 188).

34 La asimilación de la publicidad a la apariencia no es infrecuente. Cfr. BoLAFFI, ob. cit., p. 137; CORRADO, ob. cit., pp. 38 y ss. (quien afirma, sin embargo, la existencia de una clara diferenciación de los dos fenómenos; contradicción subrayada por PugliatTI, ob. ult. cit., p. 266); MENGONI, ob. cit., p. 76. 
jurídica declarada. Esta exoneración puede ser muy amplia, como ocurre en la inscripción registral —en un sector bastante circunscrito, por lo demás- y en algunas declaraciones provistas de una eficacia formal mucho más intensa, en las cuales ni siquiera la mala fe del tercero, entonces, será válida para impedir la íntegra aplicación del formalismo. En los demás casos, la exoneración opera solo en presencia de la buena fe del tercero, la cual se expresa en la especie menor de la ausencia de conocimiento. Se podrá hablar de apariencia respecto de declaraciones de este tipo, por lo tanto, solo en un sentido completamente atécnico, para indicar la protección jurídica de los terceros cuando las declaraciones no correspondan a la realidad de la situación jurídica declarada. Los instrumentos del formalismo jurídico apuntan a proteger las mismas exigencias prácticas a las cuales responde el fenómeno de la apariencia, y ello explica la confusión que se ha creado, así como la orientación seguida por la doctrina alemana. Pero donde operan los primeros — como hemos destacado- no hay razón para que opere el segundo, y este encuentra su campo de aplicación, justamente, en aquellos casos en que la misma exigencia práctica no tiene, para su protección, un instrumento rígido del formalismo jurídico. La apariencia es, ni más ni menos, un instrumento elástico, idóneo para penetrar en los campos donde el formalismo jurídico no ha tenido posibilidad de desarrollarse, y que apunta a proteger el interés de los terceros cada vez que estos no tengan una declaración formal en la cual apoyarse, pero hayan sido engañados, sin embargo, por una situación de hecho que ha manifestado como existente una realidad jurídica inexistente.

En lo señalado está la razón de la relevancia, pero a la vez el límite, de la apariencia en el ordenamiento italiano. La imperfecta organización del sistema de publicidad en nuestro derecho y el insuficiente desarrollo de los instrumentos del formalismo jurídico hacen necesario un medio que supla estas deficiencias, y que garantice la protección de intereses que se consideran preeminentes. ${ }^{35}$

Fuera de dicho papel, sin embargo, ya no es legítimo hablar de apariencia, por lo menos no en un sentido jurídicamente definido. No basta constatar que la divergencia entre lo que aparenta ser y el ser es tomada en cuenta por el derecho. Es menester dilucidar si la razón de su relevancia jurídica consiste en que aquella divergencia hace entrar en juego el sistema de intereses que vale para identificar la apariencia como una institución jurídica. ${ }^{36}$

35 Sobre las relaciones entre publicidad y apariencia, desde este punto de vista, cfr. PuglatTI, ob. ult. cit., pp. 252 y ss.; CORRADO, ob. cit., pp. 35 y ss.

36 Por dicha razón, fundamentalmente, hay que descartar que el matrimonio putativo se pueda explicar en términos de apariencia. Esta tesis, sostenida en Italia por SotGiA (Apparenza, pp. 18 y ss., y «Ancora in tema di apparenza del diritto», p. 152; BoLAfFl, ob. cit., pp. 141 y ss.; D'AMELIO, «Apparenza», p. 551) no ha resistido a la crítica: cfr. VERGA, ob. cit., pp. 198 y ss.; Puglatti, ob. ult. cit., p. 260. 


\section{La situación jurídica aparente}

La situación manifestante puede estar constituida por un hecho cualquiera; en cambio, la situación manifestada — que aparece, pero que no es real— está constituida, necesariamente, por una situación jurídica, que es normalmente la titularidad de un derecho subjetivo. ${ }^{37}$ Ello no significa que la falsa remisión realizada por la situación generadora de apariencia no pueda referirse a otra situación de hecho: pero ha de tratarse de un hecho jurídico tomado en cuenta, exclusivamente, por los efectos que produce, de manera tal que siempre se referirá a una situación jurídica. En lo anterior radica, por lo demás, una de las razones fundamentales de la relevancia para el derecho del fenómeno de la apariencia, porque la realidad jurídica escapa, por lo general, de la posibilidad de una determinación segura, y requiere, como quiera que sea, de amplias y complejas investigaciones. De hecho, los casos de apariencia que la ley prevé y regula son aquellos en los cuales esta determinación presenta mayores dificultades.

Puesto que la titularidad de los derechos subjetivos influye directamente, a su vez, en la legitimación del sujeto, la situación jurídica que aparece como existente en virtud de la apariencia es una situación de legitimación. El nexo entre apariencia y legitimación — que es válido para delimitar rigurosamente el ámbito en que opera el fenómeno- es indicado por la ley misma, la cual define al acreedor aparente como el que aparece como legitimado para recibir el pago, sobre la base de circunstancias unívocas (artículo 1189 del Código Civil), mientras que otras veces habla de titular aparente —así ocurre en los artículos 1415 y 1416 del Código Civil-. ${ }^{\text {NT }}$

37 Messineo, Manuale di dir. civ. e comm., octava ed., I, Milán, 1957, p. 139, habla de «apariencia de titularidad», como sinónimo de «apariencia de derecho subjetivo». Este es el significado más preciso en el que debe entenderse la expresión: véase también MENGONI, ob. cit., pp. 75, 137. Es discutible la extensión del fenómeno, desde el plano de las situaciones jurídicas específicas del sujeto hacia el plano de las situaciones jurídicas generales, como la capacidad y la competencia, a pesar de que el artículo 1426 y, respectivamente, el artículo 113 del Código Civil, parezcan sugerir la invocación de dicho fenómeno. Aprecia en el ocultamiento doloso de la incapacidad una hipótesis de apariencia, BolAfFı, ob. cit., p. 135; en sentido contrario, sin embargo, VerGA, ob. cit., pp. 201 y ss.; CorRado, ob. cit., p. 34; SACCO, ob. cit., p. 70 (quien es también contrario a asimilar a la apariencia la hipótesis prevista en el artículo 113 del Código Civil: ob. cit., p. 66).

NT Código Civil italiano:

«1415. Effetti della simulazione rispetto ai terzi.- La simulazione non può essere opposta né dalle parti contraenti, né dagli aventi causa o dai creditori del simulato alienante, ai terzi che in buona fede hanno acquistato diritti dal titolare apparente, salvi gli effetti della trascrizione della domanda di simulazione.

I terzi possono far valere la simulazione in confronto delle parti, quando essa pregiudica i loro diritti».

[«1415. Efectos de la simulación respecto de los terceros.- La simulación no puede ser opuesta por las partes contratantes ni por los derechohabientes ni por los acreedores del enajenante 
Se tratará, como es obvio, de una legitimación aparente ${ }^{38}$ —así lo indica, textualmente, el artículo 1189 del Código Civil—y aparente es también la titularidad del derecho subjetivo correspondiente: titularidad y legitimación que, por circunstancias de hecho, parecen existir, aunque no existen en la realidad jurídica. No hay que considerar inútil el subrayar, una vez más, la inexistencia de la realidad jurídica manifestada, porque a menudo la doctrina, cediendo a las fáciles sugestiones de las fórmulas, y falseando de raíz la perspectiva jurídica del fenómeno, ha convertido la inexistente titularidad del derecho subjetivo en la efectiva titularidad de otra posición subjetiva — poder jurídico o facultad jurídica一, y la legitimación inexistente en una legitimación efectiva, nacida de la situación de apariencia: así se persiste en seguir una tendencia muy difundida en la doctrina alemana, la cual propende a identificar los dos fenómenos, de la apariencia y de la legitimación..$^{39}$ El titular aparente del derecho subjetivo sería titular real de una situación jurídica equivalente, y el legitimado aparente sería legitimado real, en virtud de la distinta fattispecie de la cual constituye apariencia. La doctrina más atenta ha demostrado el vicio lógico que se anida en la transfiguración verbal de la titularidad inexistente en una titularidad real, ${ }^{40}$ y luego ha hecho notar, en el plano jurídico positivo, cuán

simulado a los terceros que debe buena fe han adquirido derechos del titular aparente, sin perjuicio de los efectos de la inscripción de la demanda de simulación.

Los terceros pueden hacer valer la simulación frente a las partes cuando ella perjudica sus derechos»].

«1416. Rapporti con i creditori.- La simulazione non può essere opposta dai contraenti ai creditori del titolare apparente che in buona fede hanno compiuto atti di esecuzione sui beni che furono oggetto del contratto simulato.

I creditori del simulato alienante possono far valere la simulazione che pregiudica i loro diritti, e, nel conflitto con i creditori chirografari del simulato acquirente, sono preferiti a questi, se il loro credito è anteriore all'atto simulato».

[«1416. Relaciones con los acreedores.- La simulación no puede ser opuesta por los contratantes a los acreedores del titular aparente que de buena fe hubieren realizado actos de ejecución sobre los bienes que fueron objeto del contrato simulado.

Los acreedores del enajenante simulado pueden hacer valer la simulación que perjudica sus derechos y, en el conflicto con los acreedores quirografarios del adquirente simulado, serán preferidos a estos, si su crédito es anterior al acto simulado»].

En el Código Civil peruano solo se recoge fragmentariamente, y con alguna variante, la segunda de las normas italianas: «La simulación no puede ser opuesta por las partes ni por los terceros perjudicados a quien de buena fe y a título oneroso haya adquirido derechos del titular aparente» (artículo 194).

38 Para los precedentes y los desarrollos de la idea de legitimación aparente en nuestra doctrina véase, sobre todo: FINZI, ob. cit., pp. 188 y ss.; MESSINEO, I titoli di credito, I, pp. 25 y ss.; BEтTI, Teoria generale del negozio giuridico, segunda ed., Turín, 1950, pp. 225 y ss.; MONACCIANI, ob. cit., pp. 147 y ss.; sobre el concepto, cfr. los realces de RAVÀ, T., «Legittimazione e rappresentanza indiretta nell'alienazione», en Banca, borsa tit. cred., 1953, pp. 13 y ss. Cfr., en particular, MeYer, H., Das Publizitätsprinzip, p. 95.

40 Messina, «La simulazione absoluta», ahora en sus Scritti giuridici, V, Milán, 1948, p. 103, quien ha observado, respecto del heredero aparente, que «[...] su llamada legitimación es el 
absurda es la noción de un poder o de una facultad cuyo ejercicio está condicionado a la existencia de un determinado estado subjetivo de otra persona - la buena fe del tercero-. Además, dicho poder o dicha facultad habrían sido conferidos, no en interés de su pretendido titular, sino en interés de un tercero. La expresión legitimación aparente ha tenido mayor influencia, en cambio, como indicativa de una particular hipótesis de legitimación: pero los mismos argumentos con los cuales se rechaza la teoría de la titularidad aparente como titularidad real de un poder o de una facultad son también válidos para rechazar esta configuración positiva de la legitimación aparente. ¿Qué legitimación sería la del heredero aparente si el acto de disposición a título oneroso realizado por este pudiera adquirir eficacia, aunque de forma limitada a los efectos jurídicos relativos al tercero, solo a condición de que este último actúe de buena fe? Todo intento de atribuir un contenido positivo a la expresión meramente negativa de legitimación aparente se resuelve en un juego de palabras que traiciona la verdadera naturaleza del fenómeno, el cual consiste en que el tercero de buena fe adquiere a título oneroso el derecho hereditario u obtiene la liberación del débito, a pesar de que el heredero aparente no esté legitimado a transferir y de que el acreedor aparente no esté legitimado para recibir el pago.

Apreciado desde el punto de vista del heredero aparente o del acreedor aparente, el acto, debido a la ausencia de legitimación de estos, estaría condenado a la ineficacia definitiva: si es recuperado - $y$ parcialmente - para el derecho, ello ocurre únicamente en atención a la posición del tercero de buena fe y a los intereses de este. La legitimación también está ligada al interés, y en el heredero aparente o en el acreedor aparente falta, justamente, el interés que debería constituir la base de la legitimación: tampoco podría ser tal el interés del tercero, porque este interés sirve para fundar la legitimación de este último, y no puede, por lo tanto, fundar otra legitimación al mismo tiempo.

Por otro lado, la legitimación se presenta en relación directa con los efectos jurídicos destinados a realizar el interés en que se basa la legitimación, y los efectos jurídicos que se producen en el fenómeno de la apariencia se predisponen, de manera exclusiva, en función del interés del tercero y, por lo tanto, en atención a la legitimación de este último.

La titularidad aparente y la legitimación aparente son, por lo expuesto, porciones de la fattispecie jurídica de la apariencia: elementos de hecho, mas no

reflejo de la expectativa del tercero, surgida de buena fe»: así como es inconcebible un poder que se disuelve cuando se desenvuelve frente a un sujeto de mala fe, del mismo modo es inconcebible una legitimación condicionada a un hecho subjetivo de persona distinta del pretendido legitimado. Cfr. también, en la doctrina alemana, los realces de ReGELSBERGER, Der sogenannte Rechtserwerb vom Nichtberechtigten, pp. 356 y ss.; de SoHm, Gegenstand, Leipzig, 1903, pp. 52 y ss.; StINTZING, ob. cit., pp. 366 y ss. 
de derecho. ${ }^{41}$ Aquí también la apariencia pertenece al mundo de los hechos, no al mundo de los efectos jurídicos. ${ }^{42}$

Como tendremos oportunidad de explicar más adelante, la apariencia hace gravitar la fattispecie del acto o negocio en la protección y en la posición jurídica del tercero de buena fe y en la legitimación de este. De tal forma, el efecto liberatorio del pago al acreedor aparente no se deriva de la legitimación de este para recibir el pago, sino de la legitimación del deudor de buena fe para pagar con efecto liberatorio a aquel que, por circunstancias unívocas, parece ser el verdadero acreedor; igualmente, el efecto de la adquisición al heredero aparente no se deriva de la legitimación de este para transferir el derecho hereditario, sino únicamente de la legitimación del adquirente de buena fe, motivo por el cual es más apropiado hablar, para esta última hipótesis, de una mutación jurídica de sucesión, y no de una transferencia.

\section{Apariencia, buena fe, error}

Nuestro derecho concibe el fenómeno de la apariencia, en cuanto tal, en un sentido puramente objetivo. Por otro lado, y como ya se ha advertido, se trata de un fenómeno ligado por una relación bastante íntima con el fenómeno subjetivo del error. Siendo así, los dos fenómenos —el objetivo, de la apariencia, y el subjetivo, del error-, a pesar de seguir siendo distintos idealmente y jurídicamente, operan juntos, como elementos parciales de una fattispecie compleja unitaria.

Que el elemento parcial constituido por la apariencia deba entenderse en sentido puramente objetivo es algo que resulta de las consideraciones efectuadas hasta este punto, pero que también se deduce, inmediatamente, de los textos legales. La calidad de heredero aparente, de acreedor aparente, de propietario aparente, según el dictado de las normas correspondientes, preexiste lógicamente, y a veces temporalmente, al acto o negocio que estos aparentes

${ }^{41}$ Justificadamente, RUBıNo, La fattispecie e gli effetti giuridici preliminari, Milán, 1939, p. 336, nota 3, destaca que el pretendido poder de disposición del titular aparente sería un inútil duplicado, y que carece de toda relevancia jurídica.

42 Salvatore Romano, "Osservazioni sulle qualifiche «di fatto» e «di diritto»», en los Scritti giuridici in onore di Santi Romano, IV, Padua, 1940, pp. 145, 146 nota 2, configura la apariencia en función de la antítesis por él estudiada, como situación de hecho que presenta aspectos jurídicos propios de otra situación. Por su parte, MONACCIANI, ob. cit., pp. 142 y ss., considera la apariencia, sea desde el punto de vista del hecho jurídico, sea en el aspecto del efecto jurídico, pero él también atribuye un contenido positivo a la situación jurídica aparente, definiéndola como «[...] efecto jurídico real, que presenta cierta similitud de características y de naturaleza con un efecto jurídico más rico y más pleno» (ibíd., p. 145), y reubica en esta realidad, es más, la razón por la cual «[...] es demolida, sin más la idea de la apariencia» (ibíd., loc. ult. cit.). 
titulares de derechos subjetivos celebran con el tercero: por ello, los hechos y estados subjetivos del tercero no pueden ser esenciales o, en todo caso, relevantes para la constitución y definición de estas cualidades. El carácter objetivo de la apariencia es destacado enfáticamente, sobre todo, en el artículo 1189 del Código Civil, donde el acreedor aparente es definido como aquel que aparece como legitimado para recibir el pago sobre la base de circunstancias unívocas. En esta disposición resulta evidente, principalmente, la estructura de la apariencia, en la cual, según el análisis antes efectuado, existe un fenómeno manifestado - el aparecer como legitimado para recibir el pago—, un fenómeno manifestante -las circunstancias unívocas - y un nexo puramente objetivo - sobre la base de- por el cual el segundo fenómeno manifiesta el primero con arreglo a las reglas y conexiones normales de la experiencia. El término circunstancias, empleado en el artículo 1189 del Código Civil tiene, además, un nítido tinte objetivo: dichas circunstancias son, como es obvio, las situaciones ambientales, y no hacen referencia a ninguna idea de estados de ánimo propios del sujeto que adquiere del heredero aparente. Estas circunstancias están preconstituidas al acto o negocio en el cual incide la apariencia, y existen, por lo tanto, con independencia de toda apreciación del tercero.

En consecuencia, se deben considerar fruto de un equívoco - que es mucho más grave, por su evidente oposición a la configuración legislativa del fenómeno- la afirmación de que la buena fe sería un elemento lógicamente necesario de la fattispecie. Si la ley requiere que se presente, como elemento concomitante de la apariencia, la buena fe del tercero, el nexo instituido entre ambos fenómenos es un nexo jurídico, no lógico. Con mayor razón, no puede considerarse legítima aquella tendencia doctrinal que pretende resolver la apariencia en el ámbito de la buena fe y del error.

Sostener que la apariencia no tiene ninguna relevancia autónoma, y que ella se agota enteramente dentro de los confines de la buena fe, ${ }^{43}$ de la cual constituiría una subhipótesis ${ }^{44}$ es igual de ilegítimo, por lo menos, que pretender reducir a la buena fe la usucapión o ciertas figuras de publicidad, solo porque sin la buena fe del adquirente la usucapión y aquellas figuras no producirían su efecto. En una fattispecie de estructura compleja no se puede definir el todo en función de una parte; ${ }^{45}$ tiene escaso valor el replegarse, como alguno

43 También Pugliattı, ob. ult. cit., p. 258, parece seguir esta orientación. No se puede compartir, por ello, la opinión de que «la apariencia se reduce, a fin de cuentas, al error» (MONACCIANI, ob. cit., pp. 136, 139 y ss.). En el sentido de Monacciani, véase también SAcco, ob. cit., p. 55.

44 Cfr. Pugliatti, ob. ult. cit., p. 258.

45 Venezian, ob. cit., pp. 162, se detiene, por ejemplo, en la consideración de la importancia, en el ámbito de la fattispecie global, de un elemento ulterior, el acto o negocio defectuoso por la ausencia del presupuesto de legitimación: el autor citado destaca que el acto o negocio no debe presentar ningún vicio que comprometa su existencia o eficacia. 
ha hecho, en la configuración de la buena fe en términos objetivos, a fin de salvar la peculiaridad de las hipótesis de apariencia. Así entra a tallar la idea de una buena fe objetiva, un híbrido que confunde los fenómenos y no salva nada, porque deforma, inútilmente, el concepto de buena fe, que es subjetivo, y porque no logra poner en evidencia la objetividad del concepto de apariencia. No se avanza mucho, por lo demás, y tampoco se elimina el defecto de planteamiento, cuando, manteniendo fidelidad a la concepción subjetiva de la apariencia, se intenta transponer esta presunta subjetividad desde el plano individual hacia el plano colectivo: ${ }^{46}$ esta tendencia se vincula con la teoría del error común, y representa una específica aplicación de ella a nuestro tema. En efecto, como ya hemos tenido oportunidad de señalar, los juristas franceses acostumbran asimilar a la teoría del error común las fattispecie de apariencia. Son conocidas las dudas en torno del origen y alcance del principio error communis facit ius, ${ }^{47} \mathrm{y}$ también es conocida la aversión que él ha encontrado entre los intérpretes del derecho italiano. ${ }^{48}$ Sin embargo, al margen de las oposiciones de orden general, no es difícil darse cuenta de la imposibilidad de configurar la apariencia como una situación de error común. Error común es error colectivo vigente, y es a este título que él da justificación al error del sujeto en particular. ${ }^{49}$ Pero un error colectivo vigente no es requerido en el fenómeno de la apariencia, aunque a veces, como ocurre en la hipótesis del heredero aparente, la falsa calidad del sujeto puede tener amplia difusión en la colectividad; en algunos casos, además, ella no podría ni siquiera presentarse como normal: la posición de acreedor aparente, por ejemplo, no puede tener una resonancia pública tal que constituya un conocimiento colectivo. Por ello, hay que considerar mejor la fórmula, recientemente propuesta, del error colectivo posible,$^{50}$ porque con ella, en lo sustancial, todo análisis de la situación subjetiva de los individuos o de la colectividad queda al margen de la discusión. Esta última teoría, al hablar de posibilidad, pone el acento, más que en el

46 Se trata de fórmulas bastante difundidas. MenGONI, ob. cit., p. 76, por ejemplo, afirma que la apariencia «[...consiste en un juicio impersonal, es decir, objetivo, expresado por la generalidad de los terceros». Tampoco las evita SACCO, ob. cit., p. 55, quien afirma que «[...] un hecho irreal es aparente cuando lo cree real, luego de un examen superficial, la generalidad de los terceros o, en su ausencia, un sujeto hipotético, constituido con la más lata abstracción».

47 Cfr. ValabrèGue, ob. cit., p. 81; MAZEAud, ob. cit., pp. 929 y ss.; CAPORAlı, «Error communis facit ius», en Diz. prat. dir. priv., II, Milán, s.a., pp. 871 y ss.; PugliatTI, ob. ult. cit., pp. 255 y ss.

48 Coviello, N., Manuale di dir. civ., Milán, 1910, pp. 109, 326 y ss.; Bolaffl, ob. cit., p. 140; Pugliattı, ob. ult. cit., pp. 255 y ss. Cfr. también Caporali, ob. cit., pp. 871 y ss.; De Villa, «Error communis facit ius», en Nuovo Dig. it., V, Turín, 1938, p. 482.

49 D'Amelıo, «Apparenza», p. 553.

50 La definición es de Monacciani, ob. cit., pp. 138 y ss. La adopta Puglatti, ob. ult. cit., pp. 254 y ss. Una interpretación cercana, en varios aspectos, a la de Monacciani, pero con una motivación teórica distinta, ya había sido expuesta por SACCO, ob. cit., p. 55. 
estado colectivo de los sujetos, en las causas idóneas para producirlo: y tales causas son, evidentemente, objetivas. Es válido, por lo tanto, considerar directamente - y no indirectamente, como se hace cuando se habla de posibilidad - el fundamento objetivo de la apariencia. Así hemos intentado hacerlo nosotros.

Pero si la apariencia, como elemento aislado, es algo estrictamente objetivo, ello no significa que no pueda coexistir, en una fattispecie global, con elementos subjetivos. La apariencia no puede reducirse, ciertamente, a la buena fe, pero sí puede unirse a esta última en el ámbito de una fattispecie más amplia. Eso es lo que requiere, justamente, el derecho positivo italiano. Esta coexistencia de elementos objetivos y subjetivos en el ámbito de la misma fattispecie es legítima en general, y necesaria en el ámbito de la interpretación de las disposiciones legales. No se opone a ella ninguna incompatibilidad lógica: ${ }^{51}$ no se puede confundir, en efecto, la incompatibilidad de las dos características —objetividad y subjetividad — en un mismo fenómeno, con la incompatibilidad de las mismas características en dos fenómenos distintos, al interior de una estructura global más compleja.

Los estudiosos, especialmente los más recientes, han dedicado interesantes consideraciones a las relaciones entre apariencia y buena fe. ${ }^{52} \mathrm{~A}$ pesar de cierta reserva - debida, por cierto, a la inexacta interpretación de algunas hipótesis legislativas - ${ }^{53}$ la doctrina ha tomado conciencia de la orientación de nuestro legislador, en el sentido de no reconocer eficacia a la apariencia a menos que concurra la buena fe. ${ }^{54}$ Por otro lado, los autores más sutiles configuran la buena fe, cuando esta opera con la apariencia, como una forma de error.

La apariencia y el error deben ser considerados como elementos igualmente constitutivos de la fattispecie compleja: quien pretenda valerse de la apariencia debe, por lo tanto, probar tanto el elemento objetivo cuanto el elemento subjetivo. ${ }^{55}$

51 Véase, en cambio, PugliatTı, ob. ult. cit., pp. 262 y ss., quien, partiendo de la definición de la apariencia como error colectivo posible, encuentra que existe una irreducible oposición entre este y la buena fe, la cual consiste, como la confianza, en un estado subjetivo individual y vigente.

52 Cfr., especialmente, SACCO, ob. cit., pp. 53 y ss.; MeNGONI, ob. cit., pp. 64 y ss.; MONACCIANI, ob. cit., pp. 132 y ss. (a quien se debe el estudio más profundizado de las relaciones entre apariencia y error); PuglatTI, ob. ult. cit., pp. 254 y ss.

53 Véase Bolaffl, ob. cit., pp. 133 y ss.; Corrado, ob. cit., p. 81; Sacco, ob. cit., p. 74, nota 9.

54 Entre otros: Salandra, ob. cit., pp. 62, 49: MonaCCIANI, ob. cit., p. 140. Hay quien habla de una coligación que no es necesaria, sino simplemente formal: así, además de los autores citados en la nota precedente, PugliatTI, ob. ult. cit., p. 257.

55 MenGONI, ob. cit., pp. 76, 80, 92 y ss., descarta que la buena fe forme parte de la fattispecie de la apariencia, y atribuye a la mala fe la característica de un simple requisito impeditivo de eficacia. Sin embargo, esta inversión del papel de la buena fe en la fattispecie de la apariencia se encuentra, sobre todo, en clara contradicción con la ley, la cual, al contrario 
Estos resultados deben considerarse bien afirmados en la teoría de la apariencia. Pero ellos todavía no son suficientes para una cabal definición de toda la fattispecie, ni del elemento subjetivo en particular.

\section{El error como elemento de la fattispecie compleja de la apariencia}

Llegados a este punto, y a fin de entender el juego de los intereses que involucra el fenómeno de la apariencia, así como la forma de su protección jurídica, es necesario un análisis más exhaustivo del significado y de la función del error, que constituye un elemento parcial, pero esencial, de la fattispecie compleja que se ha descrito. El análisis ha de servir, además, para aclarar los mecanismos mediante los cuales la fattispecie de la apariencia reacciona en el acto o negocio jurídico. El error en general, cualquiera que sea su forma, como acto o estado del espíritu que juzga o considera verdadero lo que es falso, o viceversa, influye negativamente en el proceso de realización de los valores jurídicos: en efecto, el comportamiento asumido en estado de ignorancia o de error puede provocar, y normalmente provoca, la lesión de un valor jurídico.

No podrían surgir dificultades relevantes si solo estuviera en juego el interés del sujeto que ignora o que incurre en el error. Las dificultades aparecen, más bien, cuando el interés de tal sujeto entra en conflicto con el interés de otros sujetos, de manera que el remedio que podría ser elegido para proteger el primero terminaría sacrificando al segundo. Esta es la razón por la cual los casos de ignorancia y de error plantean siempre problemas de ardua solución para el derecho. El derecho tiene que decidir entre dos intereses en conflicto $y$, al margen de cuál sea su decisión, se ve forzado a sacrificar uno de los intereses abstractamente merecedores de protección.

La protección del interés del cual es portador el sujeto que ignora o que incurre en error puede dar lugar, según el caso, a remedios que operan en sentidos opuestos, es decir, en el sentido de la eficacia, o bien en el de la ineficacia de los actos celebrados en estado de ignorancia o error.

El régimen del error en los negocios jurídicos pertenece a los remedios del segundo tipo. El sujeto que incurre en error manifiesta un interés que tal vez no existe en realidad; por ello, si la ley confiriera a la fattispecie negocial plena eficacia, el interés real del sujeto podría resultar comprometido. La salvaguardia

de lo que señala Mengoni, pone a cargo del que se vale de la apariencia la carga de la prueba de la buena fe (véanse, por ejemplo, los artículos 534 y 1189 del Código Civil). Contra la tesis de Mengoni, cfr. PugliatTI, ob. ult. cit., pp. 261 y ss. La jurisprudencia no ha evitado subrayar que la buena fe debe ser probada por el tercero (cfr. Corte di Cassazione, sentencia $n^{\circ} 24$, del 3 de enero de 1941). 
de este interés exigiría, entonces, el remedio jurídico de la ineficacia o el de la eficacia provisoria y removible a iniciativa del sujeto que erró. Sin embargo, en los negocios bilaterales, en los cuales la fattispecie negocial pone en juego no solo el interés del sujeto que yerra, sino también el interés del otro sujeto, una protección incondicional del primero implicaría un sacrificio igualmente incondicional del segundo. Esta es la razón por la cual el ordenamiento jurídico trata de equilibrar las dos posiciones, favoreciendo a la contraparte, aunque sin concederle una protección incondicional. La adopción de un criterio rigurosamente subjetivo, por lo tanto, comportaría la protección absoluta del sujeto que incurre en error $\mathrm{y}$, así, la ineficacia o invalidez del negocio celebrado por él en estado de error; por el contrario, la adopción de un criterio opuesto, rígidamente objetivo, exigiría protección absoluta de la contraparte, o sea, la atribución de una eficacia definitiva al negocio, a pesar del error. Una forma intermedia, que sea justa respecto de ambos intereses, se resuelve, necesariamente, en la imposición de nuevas cargas para los sujetos del negocio y, en particular, para el destinatario de la declaración del sujeto que yerra. El requisito de la reconocibilidad ${ }^{\mathrm{NT}}$ representa el instrumento del que se vale el derecho para realizar esta forma intermedia de protección de los intereses contrapuestos, y se resuelve en una carga de diligencia a cargo de los sujetos del negocio, para que se percaten del error objetivamente reconocible en el cual ha incurrido la contraparte. La reconocibilidad denota un fenómeno opuesto al de la apariencia: una realidad presente o inmediatamente deducible de la realidad presente, en virtud de una relación de manifestación adecuada. Se introduce en la actividad negocial, pues, una carga de diligencia que es, además, una forma embrional de carga de determinación. A través de esta carga, se protege el interés del sujeto que yerra; el error, entonces, puede conducir a que se proteja el interés del sujeto solo si tal protección no perjudica indebidamente el interés de la contraparte que, observando un comportamiento de diligencia ordinaria, no se hubiere percatado, porque no podía percatarse, del error cometido por el sujeto que tenía frente a él.

Sin perjuicio de lo anterior, el conflicto entre los intereses contrarios se puede presentar en forma más compleja y, desde cierto punto de vista, opuesta. En tal caso, la solución jurídica tendrá que ser también distinta y opuesta.

Esta segunda hipótesis tiene lugar cuando la divergencia entre los elementos objetivos y subjetivos no tiene que ver directamente con el interés que es fundamento del negocio, y para cuya realización se ha predispuesto el programa

NT A imitación del legislador italiano, que prescribe «[...] l'errore è causa di annullamento del contratto quando è essenziale ed è riconoscibile dall'altro contraente» (artículo 1427 del Código Civil), el peruano estatuye, con una imprudente generalización de una norma concebida — como es fácil de notar — para el derecho contractual, que «[...] el error es causa de anulación del acto jurídico cuando sea esencial y conocible por la otra parte» (artículo 201). 
negocial, sino con un interés ajeno al negocio, del cual es portador un sujeto distinto. En atención a la incompatibilidad que se postula, entre el interés interno y el externo, si el ordenamiento jurídico atribuye preeminencia al interés externo, debe negar eficacia al negocio jurídico en la parte relativa al interés interno incompatible; en cambio, si la preeminencia es atribuida al interés interno, debe retirar su protección al interés externo, y atribuir al negocio eficacia jurídica definitiva, a pesar del error.

Puesto que el interés externo es, por definición, un interés jurídico, el cual ha sido constituido y ha obtenido la garantía del derecho con anterioridad a la constitución del interés negocial, una rigurosa aplicación del principio temporal en la protección jurídica debería conducir a una negación sistemática de protección y, por ello, al sacrificio sistemático del interés negocial posterior. Dicha solución se concretaría en la imposición de una carga ilimitada de determinación de la realidad, por cuenta de los sujetos, y, por consiguiente, en una obstrucción paralizante del desenvolvimiento de las mutaciones jurídicas, que sería inadmisible, con mayor razón, en un ordenamiento moderno, en el cual la exigencia de agilizar el comercio jurídico va acentuándose continuamente, a medida que aumenta el número de sujetos de la comunidad, y que se hace más intenso y rápido el ritmo de vida de estos. Las legislaciones tienden a conciliar estas exigencias opuestas ${ }^{56}$ — respetar los intereses jurídicos preconstituidos, por un lado, y favorecer la agilidad de las mutaciones jurídicas, por otro- a través de la disposición de medios objetivos de conocibilidad de los intereses, y de la limitación, en distinta medida, de la carga de determinación de la realidad por cuenta de los sujetos. De tal manera, el ámbito de intangibilidad de los intereses preconstituidos se va restringiendo $y$, a medida que se limita la carga de determinación por cuenta de los terceros, se introducen y agrandan las cargas de conservación de los intereses por cuenta de los titulares. Estos últimos, por lo tanto, no pueden considerarse satisfechos con la obtención de la garantía originaria del derecho para sus intereses, sino que deben hacerse merecedores, así mismo, de la conservación de dicha garantía, con la adopción de un comportamiento diligente, capaz de no poner en riesgo, por imprudencia o por determinación consciente, la protección de la ley.

En el ordenamiento italiano, el caso límite está constituido por el mecanismo de la publicidad, en el cual la protección de los intereses contrapuestos, internos y externos al acto o negocio, del sujeto que lleva a cabo el acto o negocio, o de los terceros, se desenvuelve en un plano esencialmente formal. La ambivalencia del mecanismo, que preserva en forma rígida y, por ello, con

56 A esto debe asociarse la conocida dialéctica entre protección de los derechos subjetivos y protección de los tráficos, sistemáticamente invocada por los estudiosos de la publicidad y de la apariencia, y que ha sugerido el título de un estudio harto famoso de EHRENBERG, Rechtssicherheit und Verkehrssicherheit, en Jahrb. für die Dogmatik, 1904, pp. 273 y ss. 
la garantía de la mayor eficiencia, tanto el interés interno cuanto los intereses externos, objetiviza al máximo grado la carga de determinación de los terceros, así como la carga de conservación del sujeto del acto o negocio, de modo que en tales cargas y en los efectos de su inobservancia no inciden factores de carácter subjetivo - formas de conocimiento o ignorancia o valoraciones de posibilidad concreta-: si se quiere hablar de autorresponsabilidad en relación con esta institución, es necesario especificar que se trata de una hipótesis de autorresponsabilidad objetiva. ${ }^{57}$

Empero, fuera de la institución de la publicidad, la composición del conflicto entre el interés interno y el interés externo debe hallar su fundamento en algún elemento de subjetividad. Las dos cargas, es decir, la del sujeto del acto o negocio y la de los terceros, deben tener un fundamento subjetivo en mayor o menor media intenso, y la autorresponsabilidad respectiva debe plantearse como autorresponsabilidad subjetiva, necesariamente.

El caso límite opuesto al de la publicidad está representado por la relevancia de toda anomalía subjetiva que haya obstaculizado el funcionamiento de la carga de conservación o de determinación. Puesto que ambas cargas se encuentran en posición opuesta, cada vez que se amplía la relevancia de la carga de determinación se restringe en la misma medida la relevancia de la carga de conservación, y viceversa; por lo tanto, toda limitación de la carga de determinación conlleva una acentuación de la carga de conservación. La dosificación entre ambas cargas puede ser distinta, dependiendo de si la ley atribuye preeminencia al interés preconstituido o al interés posterior. Así, algunas veces bastará el estado de ignorancia del titular para fundamentar la preeminencia del interés sobrevenido, otras veces se requerirá, para tal fin, el estado de error, y otras veces será necesario un estado de error caracterizado por causas específicas. Para determinar la subordinación del interés preconstituido, a su vez, se puede requerir que el titular haya sido el que determinó el estado de ignorancia o de error del titular del interés sobrevenido, aunque también es posible que se prescinda de un comportamiento específico de dicho sujeto.

Entre estas hipótesis intermedias se ubica la apariencia. En ella también están en juego dos intereses: uno preconstituido y de antemano garantizado por la ley, el otro sobrevenido y vinculado con un acto o negocio jurídico. Como se trata de dos intereses incompatibles, el derecho tiene que realizar una elección: si escoge el primero, se debe negar al acto o negocio aquella eficacia que sería necesaria para garantizar el segundo; si escoge el segundo, será necesario dar eficacia al acto o negocio, con el consiguiente sacrificio del primero. En los casos de apariencia, la ley preselecciona el interés sobrevenido, a condición de que la falta de determinación por parte de su titular se concrete en un

57 Sobre este punto, cfr. Pugliatti, ob. ult. cit., pp. 423 y ss. 
error, y de que este error tenga como causa una situación objetiva idónea para justificarlo.

Por lo tanto, la ruptura del esquema rígido del principio de causalidad, a través del fenómeno de la apariencia, introduce un nuevo riesgo para el titular del derecho subjetivo, el cual puede verse privado de tal derecho, no solo por efecto de las causas extintivas ordinarias, sino también como consecuencia de un acto o negocio en el cual él no haya participado, pero que tendrá, de todas maneras, eficacia en su esfera jurídica. Es un riesgo que ocasionalmente obedece a un comportamiento del sujeto - de negligencia o de imprudencia, e incluso de la premeditación consciente de la situación de apariencia- $y$, por consiguiente, a la inobservancia de una carga jurídica. A veces, sin embargo, opera de la manera más objetiva — con prescindencia de toda consideración del titular real del derecho- y constituye, entonces, la expresión más auténtica de la elección que el legislador realiza entre los dos intereses en conflicto.

Lo expuesto autoriza a concluir que mediante la fattispecie de la apariencia, la ley protege de forma directa e inmediata el interés de aquel que obra en estado de buena fe objetivamente excusable. El interés del titular de la esfera jurídica comprometida por la recuperación del acto o negocio podrá ser objeto de un régimen jurídico distinto, que se diferenciará según las relaciones que existan con el legitimado aparente; solo que esta protección es externa y consiguiente, y carece de validez para identificar el significado jurídico del fenómeno de la apariencia.

\section{El error en la institución de la apariencia y su excusabilidad objetiva}

El error que la apariencia determina en el sujeto no es distinto, en sus características esenciales, del error que vicia la voluntad y que ocasiona la invalidez del negocio jurídico. Un convencimiento erróneo cualquiera, acerca de la existencia de una situación jurídica, no es suficiente para configurar la fattispecie de la apariencia ni para determinar los efectos jurídicos correspondientes. La ley requiere que la convicción errónea sea causada por una situación de hecho tal que un sujeto promedio cualquiera de la colectividad habría incurrido en el mismo error. ${ }^{58}$ Debe tratarse, por lo tanto, de una situación de hecho capaz de hacer caer en engaño sobre la existencia de la situación jurídica a cualquier persona de diligencia y atención normales, ${ }^{59} \mathrm{o}$ sea, de un

58 MONACCIANI, ob. cit., p. 138, afirma que «[...] lo esencial es que todo tercero pueda resultar engañado».

59 En dicho sentido, pero solo en dicho sentido, se puede afirmar que la apariencia existe erga omnes: SACCO, ob. cit., p. 55. 
error excusable ${ }^{60} \mathrm{La}$ excusabilidad no debe ser considerada, exclusivamente, en relación con las circunstancias del caso especifico, sino también atendiendo, sobre todo, a situaciones de hecho típicas, ligadas por un vínculo relacional normal con las situaciones jurídicas erróneamente consideradas existentes. En el elemento objetivo del error se refleja, pues, aquel aspecto de objetividad que hemos señalado previamente, a la vez que asume un sentido definido el nexo que la doctrina ha destacado entre el fenómeno de la apariencia y la idea de colectividad. La excusabilidad del error en la apariencia debe ser interpretada en sentido objetivo, y también en sentido objetivo se tiene que entender la reconocibilidad del error, cuando este opera como vicio del negocio jurídico.

En la fattispecie de la apariencia, por lo tanto, el elemento subjetivo está dado por el error objetivamente excusable del tercero. Es a este requisito del error que alude, entonces, nuestra jurisprudencia, cuando requiere, además de la buena fe, que se determine, según el caso, la razonabilidad de la confianza, a fin de que la protección de la apariencia no se resuelva en una ventaja indebida para aquel que no se cuidó de determinar la realidad de las cosas, y que prefirió confiar en la apariencia de los hechos.

Como se ha visto, el error recae en la existencia de una situación jurídica válida. La fattispecie de la apariencia tiene razón de operar solo cuando la situación legitimante que el sujeto, a causa de un error objetivamente excusable, consideraba existente y válida, o no existía en realidad o no existía de forma válida. Un error como este puede tener lugar a través de la mediación de otro hecho jurídico - error sobre la inexistencia de un hecho jurídico que haya cancelado la situación jurídica legitimante- pero tiene como su elemento necesario y último a esta situación jurídica. Aquí no es importante decidir si se trata de error de derecho ${ }^{61}$ — según la tendencia general propuesta por aquellos que consideran que esta figura se presenta todas las veces que la falsa representación mental del sujeto se refiera a una situación jurídica- o si se trata de un error de hecho, como debería concluirse si se sigue el punto de vista de

60 El elemento de la excusabilidad del error en el fenómeno de la apariencia es subrayado, en particular por la jurisprudencia, la cual hermana la excusabilidad con la razonabilidad de la confianza. Cfr., entre los numerosos fallos: Corte di Cassazione, sentencia n ${ }^{\circ} 1151$ del 12 de abril de 1954 (en Foro it. Rep., 1954, voz Obbl. contr., 1796, 50); Corte di Cassazione, Sezioni Unite, sentencia no 3962 del 31 de diciembre de 1955 (en Giust. civ. Rep., 1955, no 39); Corte di Cassazione, sentencia no 3389 del 8 de octubre de 1956 (en Foro it., 1957, I, col. 1473); Corte di Cassazione, sentencia n 2615 del 4 de julio de 1957 (en Giust. civ. Mass., 1957, p. 1007); Corte di Cassazione, sentencia no 3706 del 10 de octubre de 1957 (en Giust. civ. Mass., 1957, p. 1391); Corte di Cassazione, sentencia no 3932 del 17 de octubre de 1957 (en la misma revista, 1957, p. 1486). ReDENTI, Dei contratti nella pratica commerciale, Padua, 1931, invirtiendo la relación entre apariencia y error excusable, destaca que este último no sería otra cosa que un aspecto del principio, más amplio, de la apariencia jurídica.

61 En tal sentido, MOnACCIANI, ob. cit., p. 142. 
aquellos que limitan el ámbito del error de derecho a la hipótesis en que la falsa representación del sujeto se refiere a un punto del derecho objetivo. Lo que podría conducir a esta segunda solución es la circunstancia de que el error, a pesar de referirse a la existencia de la situación jurídica legitimante, no deriva de una apreciación errada de las condiciones prescritas por la ley para que dicha situación exista, sino de un conocimiento errado del conjunto de circunstancias que habría sido necesario conocer exactamente y enteramente, como para poder fundar en él una justa inferencia en torno de la situación jurídica. Si el sujeto hubiese tenido forma y posibilidad de extender el ámbito de sus conocimientos a todas las circunstancias de hecho directamente o indirectamente influyentes en la existencia y en la validez de la situación jurídica, no habría incurrido en error.

La presencia de un error objetivamente excusable es un elemento necesario para complementar la fattispecie de la apariencia, pero es también un elemento suficiente. No es necesario, en particular, que el error del tercero sea causado por culpa o dolo de otro, y, para ser más precisos, del titular del derecho subjetivo. Si se presenta culpa o dolo de este último, estaremos ante una hipótesis especial de apariencia, y será conveniente distinguirla de la primera. Hablaremos, entonces, de apariencia pura, cuando el error sea causado solo por la situación de hecho que manifiesta falsamente una situación de derecho; hablaremos de apariencia culposa, en cambio, cuando el error del tercero sea causado por el comportamiento culposo o doloso del titular real del derecho subjetivo. Esta distinción es de notable importancia en lo concerniente a la posibilidad de una interpretación analógica de las normas que se refieren a la apariencia. Una hipótesis característica de apariencia culposa se presenta en materia de simulación, cuando el titular real determina conscientemente aquella situación de titularidad aparente que es capaz de inducir a error a los terceros.

\section{La fattispecie de la apariencia y su eficacia jurídica: la noción de error subsanante}

Ya hemos explicado que la apariencia no constituye una fattispecie autónoma, sino que opera en el ámbito de un acto o de un negocio jurídico. ${ }^{62} \mathrm{El}$ acto o negocio es afectado por una irregularidad de origen, atribuible a la inexistencia

62 La tentativa barroca de la doctrina alemana, de extender el ámbito del fenómeno a los actos ilícitos, ha fracasado por completo. Cfr., sobre este punto, MEYER, ob. cit., p. 398; MossA, «Il registro di commercio», pp. 69 y ss. Por su parte, Allorio, "Apparenza giuridica e cosa giudicata», ahora en su volumen Problemi di diritto, II, Sulla dottrina della giurisdizione e del giudicato, Milán, 1957, pp. 203 y ss., deduce, a partir de la observación de que la apariencia, y la buena fe en general, puede valer solo frente al tercero contratante (fórmula demasiado restringida, por lo demás), que no puede hablarse de estos fenómenos frente al tercero 
de la situación jurídica que constituye su presupuesto ordinario según la correspondiente previsión normativa: la posición de heredero, de titular no precario ni simulado del derecho enajenado, de acreedor, etcétera. La situación jurídica presupuesta es, para ser precisos, aquella situación jurídica sobre cuya existencia recae el error objetivamente excusable. Y puesto que esta situación opera como fuente de legitimación respecto del acto o del negocio, su ausencia debería conducir, directamente, a la ineficacia. El papel jurídico de la apariencia es, justamente, obviar lo más posible esta causa de ineficacia, y permitir, por lo tanto, que el acto o negocio irregulares produzca de todas maneras los efectos que les son propios. Así, ella permite recuperar para el derecho una fattispecie que de otra forma sería inútil jurídicamente. En el conflicto que se establece entre el interés del legitimado efectivo -interés que puede ser preservado solo a través de la ineficacia-y el interés del tercero que, a causa de la apariencia, ha incurrido en un error objetivamente excusable -interés que, a diferencia del primero, no puede ser satisfecho sino por medio de la eficacia, la ley otorga preeminencia a este último. El error objetivamente excusable en la fattispecie de la apariencia despliega, entonces, una acción subsanante, y se contrapone a la figura ordinaria de error, que despliega, por el contrario, una acción viciante: el primero gana para el derecho una fattispecie que, de otra manera, resultaría definitivamente ineficaz; el segundo introduce en la fattispecie un germen invalidante, capaz de erradicar la eficacia precariamente atribuida al acto. La adquisición al que no es heredero o al que no es titular, por ejemplo, que como tal es ineficaz por defecto de legitimación del enajenante, es válida para hacer que el tercero, en el cual la apariencia ha generado un estado de error, asuma el derecho objeto de adquisición. Del mismo modo, el pago del deudor que incurre en error, a causa de las circunstancias que hacen aparecer al destinatario como acreedor, produce la liberación de la deuda. ${ }^{63}$

litigante: el tercero no puede hacer valer contra el verdadero titular de la relación la sentencia obtenida contra un titular aparente. Sin embargo, hay que entender que así como se puede oponer al titular real el acto o negocio realizado frente al titular aparente, de la misma manera se puede oponer a él una cosa juzgada, establecida frente al titular aparente y relativa a cierto acto o negocio.

63 No parece ser legítima la objeción planteada, desde un punto de vista lógico, por VENEZIAN, ob. cit., p. 164, contra la idea de «[...] atribuir al error una influencia positiva, y hacer de aquella divergencia una razón para que el efecto tenga lugar, como si la representación fuera conforme a la voluntad». El problema de la influencia, positiva o negativa, del error sobre la eficacia dela acto o negocio es un problema de puro derecho positivo, y no compromete la lógica más que cualquier otra cuestión de intereses socialmente relevantes. PugliaTTI, ob. ult. cit., p. 259, considera que «[...] se puede destacar, sin mayor esfuerzo, que el ordenamiento jurídico bien puede atribuir una eficacia positiva al error, aun cuando éste, en el campo psicológico, tiene una eficacia negativa». Por su parte, VERGA, Errore e responsabilità nei contratti, Padua, 1941, p. 113, asocia los efectos positivos con la buena fe. 
Debe precisarse, sin embargo, que el error subsanante no actúa en la fattispecie de la forma íntegra en que opera el error viciante. El primero siempre deja residuos que el derecho tiene que tomar en cuenta, a través de la predisposición de efectos jurídicos suplementarios. Hemos visto que la fattispecie en la cual incide el fenómeno de la apariencia hace entrar en juego dos intereses principales: el del legitimado real y el del tercero. La recuperación de la fattispecie a causa de la apariencia y del error subsanante está en función del interés del tercero; por ello, se garantizan los efectos jurídicos, y solo los efectos jurídicos, ligados con este interés. El defecto de legitimación da lugar a un vicio que solamente puede subsanarse de forma parcial, en lo concerniente a los efectos jurídicos relativos al sujeto que incurre en error: el significado fundamental de la apariencia consiste en dicha subsanación. En el caso del pago al acreedor aparente, por ejemplo, se produce el efecto liberatorio propio del cumplimiento; no se produce, en cambio, el efecto complementario, satisfactorio del acreedor, porque aquel que recibe el pago no es el acreedor real; a su vez, el acreedor real, que es el único sujeto respecto del cual se puede hablar de una eficacia satisfactoria, no es el beneficiario del pago. De igual forma, en la adquisición al heredero aparente, la asunción del derecho objeto del negocio por parte del adquirente asegura a este acto los efectos jurídicos, justamente, por el lado del adquirente; del lado opuesto, en cambio, no se puede producir el efecto propio de la enajenación, porque el derecho enajenado no se encuentra en la esfera jurídica del enajenante. En los dos casos indicados - como en todos aquellos en los que se presenta la figura de la apariencia- quedan residuos jurídicos, vinculados con las relaciones entre titular aparente y titular real; residuos que deben resolverse con efectos jurídicos ulteriores y distintos.

Considerando todo lo anterior, creemos que el fenómeno de la apariencia no puede explicarse recurriendo al principio de los hechos equivalentes. ${ }^{64} \mathrm{El}$ mecanismo rígido de la subrogación legal de elementos de la fattispecie no refleja el modo en que opera la apariencia. La legitimación y la apariencia no son hechos jurídicamente equivalentes, como tampoco lo son el acto o negocio no viciado por defecto de legitimación y el acto o negocio recuperado mediante la apariencia.

\section{Consideraciones conclusivas: el problema de los límites de la institución de la apariencia}

No se puede poner punto final a esta resumida exposición sin hacer referencia, cuando menos, a aquel que es, tal vez, el problema práctico más importante de

Sacco, ob. cit., pp. 56 y ss.; Pugliattı, ob. ult. cit., p. 253. 
toda la doctrina de la apariencia: el de los límites de aplicación de la categoría en el derecho positivo italiano y, por lo tanto, el problema del carácter taxativo o no de las hipótesis legalmente previstas.

Por lo general, la doctrina muestra hostilidad ante la extensión de los confines del fenómeno, y no solamente descarta la legitimidad de la formulación de un principio general que integre el sistema de nuestro derecho positivo sino también la admisibilidad de una interpretación analógica de las normas que regulan hipótesis de apariencia. ${ }^{65}$ Esta tendencia se opone a otra - escasamente representada, a decir verdad, entre los juristas italianos-, que ve en la apariencia una de las instituciones fundamentales, y de mayor empleo, en nuestro ordenamiento ${ }^{66}$ Entre estos dos puntos de vista opuestos, se insinúa una corriente moderada, que no descarta a priori el recurso a la analogía, pero que tampoco admite la formulación de reglas demasiado generales. ${ }^{67}$

La jurisprudencia ha recibido la influencia directa del contacto con las necesidades prácticas. Aunque no faltan - especialmente en los fallos de las instancias de mérito- afirmaciones decididas de la extrañeza del principio de la apariencia a nuestro derecho positivo, ${ }^{68} \mathrm{y}$ del carácter taxativo de las hipótesis legislativamente previstas, ${ }^{69}$ la jurisprudencia no ha refutado, en modo alguno, criterios amplios en la interpretación de las normas en particular. Así, la norma sobre las adquisiciones a título oneroso al heredero aparente ha sido empleada para la protección de los terceros de buena fe que hubieren estipulado convenciones onerosas con los administradores de una herencia yaciente o suspendida, aunque el nombramiento de estos fuera declarado irregular o nulo con posterioridad..$^{70}$ También ha sido utilizada para considerar válidas las

65 Véase, especialmente, Stolfi, G., ob. cit., pp. 35, 37, 40; VerGA, «Osservazioni in tema di apparenza», pp. 195 y ss. En ocasión del análisis de las distintas normas: Coviello, L., «La rappresentanza dei non concepiti e la buona fede dei terzi», en Foro it., 1932, I, cols. 1315 y ss.; Cariota Ferrara, L'acquisto "a non domino», Sassari, 1934, pp. 44 y ss., y del mismo autor, Il negozio giuridico nel diritto privato italiano, Nápoles, 1948, pp. 70 y ss., 700 y ss.; Nıcolò, «La cosiddetta procura apparente», en Foro lomb., 1935, I, pp. 559 y ss.; SEGNI, "Osservazioni in tema di erede apparente», en Foro it., 1935, I, cols. 104 y ss. Toman partido por un criterio rígido también CORRADO, ob. cit., pp. 22 y ss.; y MONACCIANI, ob. cit., p. 142.

66 Mossa, La dichiariazione cambiaria, pp. 305 y ss.; Messineo, I titoli di credito, I, pp. 29 y 30 nota (1). Cfr. también D'AmeLıo, «Apparenza», pp. 551 y ss.

67 SACCO, ob. cit., pp. 62 y ss., 76; del mismo autor, "Affidamento», en Enciclopedia del diritto, I, Milán, 1958, pp. 661 y ss.

68 Corte d'Appello di Milano, sentencia del 22 de abril de 1955, en Giust. civ. Rep., 1956, p. $2075, n^{\circ} 60$.

69 Corte d'Appello di Palermo, sentencia del 28 de mayo de 1955, en Giust civ. Rep., 1955, p. 2134, no 44; Corte d'Appello di Palermo, sentencia del 5 de octubre de 1955, en la misma revista, 1956, p. 2075, nº 61.

70 Corte di Cassazione, Sezioni Unite, sentencia del 21 de marzo de 1926, en Mon. trib., 1926, p. 38, citada por D'AMELIO, «Apparenza», p. 551. 
convenciones a título oneroso entre los terceros de buena fe y el futuro padre de los hijos concebidos, el cual, a pesar de no tener atribución legítima para representarlos, administrara notoriamente los bienes de estos, sin ninguna oposición. ${ }^{71}$ En cuanto a la norma sobre el pago al acreedor aparente, hay que referir que ya la aplicación del artículo 1242 del Código Civil de $1865,{ }^{\mathrm{NT}} \mathrm{de}$ dicción restringida si se le compara con el correspondiente artículo 1189 del Código Civil vigente, había sido extendida al pago realizado al apoderado aparente. ${ }^{72}$ Es más, si se quisiera fijar la orientación de los fallos jurisprudenciales más recientes, habría que afirmar que el sentido seguido es el reconocimiento de la apariencia como principio general, aplicable todas las veces en que la situación objetiva de la que deriva la errónea inferencia del tercero de buena fe sea causada por un comportamiento doloso o culposo del titular real. Hay aplicaciones importantes que la jurisprudencia ha hecho en materia de mandato, al considerar válido y vinculante para el pretendido mandante el negocio celebrado por el pretendido mandatario, cuando la calidad aparente de este último se hubiere debido a un hecho, incluso a un hecho culposo, del primero. ${ }^{73}$ Se ha llegado a afirmar que el mandatario aparente da pie a la responsabilidad extracontractual indirecta del pretendido mandante, por los hechos dolosos o culposos cometidos en ocasión del desenvolvimiento del mandato. ${ }^{74}$

71 Corte di Cassazione, sentencia del 3 de mayo de 1926, en Giur. it., 1926, I, col. 968; sentencia del 13 de junio de 1928, en la misma revista, 1928, I, col. 1003; sentencia del 22 de mayo de 1931, en la misma revista, 1931, I, col. 1315. Todas citadas por D'Amelı, loc. ult. cit.

NT Código Civil italiano de 1865:

«1272. Il pagamento fatto in buona fede a chi si trova nel possesso del credito, è valido, ancorchè il possessore ne abbia in appresso sofferta l'evizione».

[«1272. El pago hecho de buena fe a aquel que se encuentra en posesión del crédito es válido aunque luego el poseedor sufra su evicción»].

El sentido de esta norma del viejo Código Civil italiano (inspirada, a su vez, en el artículo 1240 del Code Napoléon: «Le paiement fait de bonne foi à celui qui est en possession de la créance est valable, encore que le possesseur en soit par la suite évincé») informa el artículo 1225 del Código Civil peruano: «[...] extingue la obligación el pago hecho a persona que está en posesión del derecho de cobrar, aunque después se le quite la posesión o se declare que no la tuvo».

72 Cfr. GiorgianNi, «In tema di pagamento al creditore apparente», en Foro pad., 1953, cols. 323 y ss., y allí, citas de jurisprudencia y de doctrina.

73 Cfr., entre los numerosos fallos al respecto: Corte di Cassazione, sentencia $\mathrm{n}^{\mathrm{O}} 1440$ del 10 de junio de 1949, en Giur. compl. Cass. civ., 1949, II, pp. 516 y ss.; Corte d'Appello di Milano, sentencia del 17 de mayo de 1955, en Foro pad., 1955, II, col. 54. Para una fattispecie peculiar, véase: Corte d'Appello di Genova, sentencia del 9 de marzo de 1956, en Giust. civ. Rep., 1956, voz «Obblig. e contr.», p. 2075, n 66. Para la doctrina, por lo general hostil frente a esta aplicación de la institución de la apariencia, cfr. DE MARTINI, "Apparenza di procura institoria e terzi di buona fede», en Giur. compl. Cass. civ., 1944, pp. 438 y ss.

74 Corte di Cassazione, sentencia no 722 del 17 de marzo de 1950, en Giur. compl. Cass. civ., 1950, III, pp. 240 y ss. La doctrina es contraria: cfr., especialmente, SANTORO PASSARELLI, «Responsabilità del fatto altrui, mandato, contratto di lavoro gestorio», en Foro it., 1937, IV, 
Las hipótesis más frecuentes en las cuales la jurisprudencia ha recurrido al principio de la apariencia se refieren, sobre todo, al campo de las sociedades, donde se ha formulado la regla de que aunque la entidad no exista como realidad jurídica, aquellos que se comportan exteriormente como socios asumen in solidum, frente a los terceros, obligaciones sociales, como si la sociedad existiera realmente. ${ }^{75}$ Otro tanto ha ocurrido en materia de títulos valores, especialmente en lo tocante al problema de la identificación del titular en la negociación de los títulos a legitimación real, supuesto en el que se ha considerado insuficiente la determinación de la identidad del poseedor, y se ha requerido, en aplicación del principio de la apariencia - por lo general invocado con un papel restrictivo-, una investigación de todas las circunstancias merecedoras de consideración. ${ }^{76}$ También en materia de empresas se ha recurrido al principio, al afirmarse la titularidad aparente de esta cuando la cesión o el arrendamiento del local comercial se han producido de manera tal que se causa en los terceros un erróneo convencimiento acerca de su titularidad. ${ }^{77}$

No creemos que sea posible poner en cuestión la legitimidad del principio jurídico de la apariencia, deducido de inequívocas disposiciones de nuestro derecho positivo. Tampoco creemos que se deba negar a dicho principio una amplitud que trascienda del ámbito de las distintas figuras que se han regulado legislativamente, en relación con las cuales hemos recordado — para desarrollar con mayor comodidad nuestro razonamiento— solo las más conocidas y

cols. 329 y ss.; DISTASO, «Responsabilità extracontrattuale del mandante e suoi effetti rispettoalla tutela del terzo. Apparenza del diritto, applicabilità e limiti di essa», en Giur. compl. Cass. civ., 1945, II, pp. 516 y ss.; y FACCIANO, «Apparenza del diritto e responsabilità del mandante per fatto doloso o colposo del mandatario», en Giur. compl. Cass. civ., 1950, III, pp. 230 y ss.

75 Corte di Cassazione, sentencia n 2718 del 12 de agosto de 1953, en Foro it. Mass., 1953, col. 517. Cfr. también, entre otras muchos otros fallos: Corte di Cassazione, sentencia n 1747 del 16 de junio de 1952, en Dir. fall., 1952, II, p. 253, y sentencia no 2711 del 12 de agosto de 1953, en Foro it., 1953, I, col. 1408. Sobre el problema de la llamada «sociedad aparente» cfr., en la doctrina: HeINITZ, «Apparenza del diritto e simulazione di società», en Riv. dir. comm., 1945, II, p. 63; Mıcclo, «Appunti sui limiti del concetto di apparenza nel diritto", en Giur. compl. Cass. civ., 1950, II, pp. 310 y ss.; DE MARCO, "Società di fatto e apparenza giuridica», en la misma revista, 1953, III, pp. 179 y ss.; BIGIAVI, «Società occulta, società palese, società apparente», en Riv. dir. civ., 1957, II, pp. 528 y ss.; CALUsI, «Apparenza del diritto e società commerciali», en Dir. fall., 1957, I, p. 270.

76 Cfr. Corte di Cassazione, sentencia no 3046 del 24 de octubre de 1952, en Foro it., 1953, I, col. 1470; sentencia $n^{\circ} 2040$ del 2 de julio de 1953, en Giust. civ., 1953, p. 2193; sentencia no 3461 del 20 de octubre de 1953, en Giust. civ., 1953, p. 980. En la doctrina, la cuestión ha sido examinada, entre otros, por FERRI, G., "Titoli girati in bianco e buona fede nell'acquisto», en Banca, borsa, tit. di cred., 1953, II, p. 116; y por De Semo, "Sulla identificazione del portatore di un titolo cambiario girato in bianco», en la misma revista, 1956, II, p. 148.

77 Característica es la hipótesis decidida en la sentencia de la Corte di Cassazione $n^{\circ} 3389$, del 8 de octubre de 1956, en Giust. civ. Rep., 1956, p. 256, nº 16. 
certeras. En tal sentido, debería crear convicción el amplio empleo que la jurisprudencia viene haciendo del principio, lo cual representa un indicio indudable de la distinta perspectiva que el principio ha asumido en el derecho viviente, y que no puede ser ignorada por la ciencia jurídica.

La legitimidad del principio, sin embargo, no puede justificar empleos incautos de este, especialmente en lo relativo a fattispecie que ya disponen de un régimen cabal en nuestra legislación. Por dicha razón, hay que considerar riesgosa la invocación del principio que la jurisprudencia ha hecho en materia de mandato, y respecto del régimen de la circulación de los títulos valores. También debe advertirse, y con mayor razón, que hay que interpretar las normas que regulan hipótesis de apariencia pura, es decir, aquellas en las cuales la situación objetiva que ha provocado el error del tercero no es atribuible a dolo o culpa del titular real del derecho subjetivo. Esta, por lo demás, es la tendencia seguida por la jurisprudencia, que, en la aplicación del principio más allá de los casos previstos específicamente por la ley, no sobrepasa jamás los confines de aquella figura que hemos llamado apariencia culposa. 